Social Work Practice, Data, Time and Biopolitics: Looking at Short-Term RFPs in Contemporary Community Practice in a Canadian Context

\title{
By
}

\section{Eric Levitt}

A thesis submitted to the Faculty of Graduate and Postdoctoral Affairs in partial fulfillment of the requirements for the degree of

\section{Master \\ Of}

\section{Social Work}

Carleton University, Ottawa, Ontario

(C) 2021 Eric Samuel Levitt 


\begin{abstract}
My study uses Discourse Analysis (Garrity, 2007; Jäger, 2004) to read short-term Request for Proposals (RFPs) to study the relationship between linear temporality, community work and how governments produce vulnerable subjects through data. In particular, I am interested in the ways that linear time serves as a backdrop facilitating the datafication (Dijk, 2014) of practice, and the shift from the relational to the informational in social work practice (Parton, 2008). To get a sense of how linear time and the use of data is potentially implicated in the construction of knowable and governable subjects, I utilize a conceptual framework of Biopower (Cruikshank, 1999; Million, 2013). This study hopes to contribute to relevant social work and communications literatures by focusing on data, subjectivity, linear time as a tool of social control and contemporary social work practice.
\end{abstract}




\section{Acknowledgments}

There are many people who I would like to thank in helping me formulate, write and edit this essay. I would like to thank Dr. Sarah Todd for her supervision, for always finding time to meet with me, for providing insightful comments and advising me on theoretical matters. I would also like to thank Dr. Sandra Robinson for her supervision, for making time to talk about my project and for her insightful comments and reading suggestions. I would like to thank my friends who have listened to me go on and on about my topic for over a year now. I would like to thank my friend, Perry, a dedicated study partner and smart reader of theory. I also want to thank my partner, Connor, who has patiently listened to me complain about social work the most out of anyone I know and for encouraging me to continue with this essay when it might have been easier not to. 


\section{Table of Contents}

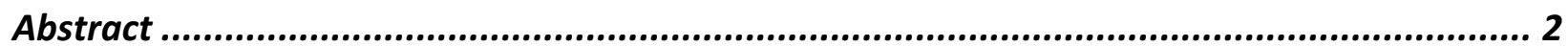

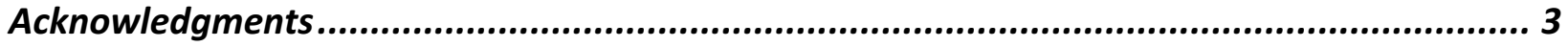

List of Appendices................................................................................................ 6

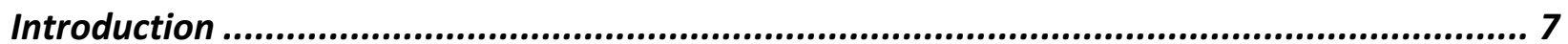

What is an RFP and why are they important to social work? ..............................................................

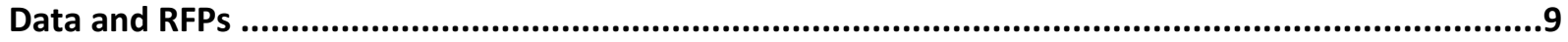

Neoliberal governance, NGOs and funding as control .................................................................10

Grants are increasingly short-term .......................................................................................11

How Linear Time is Understood in this Essay. ..........................................................................12

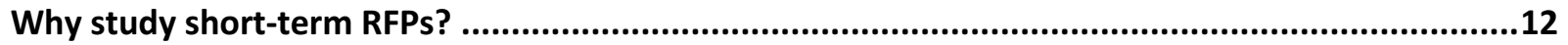

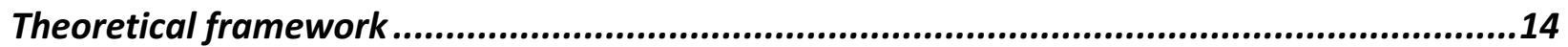

Biopolitics, imperatives of healing and empowerment, and social intervention as control..............14

Million, Cruikshank and biopolitical management of people............................................................16

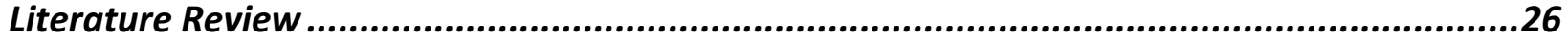

Neoliberal Restructuring of Health and Social Service Provision in Canada ....................................26

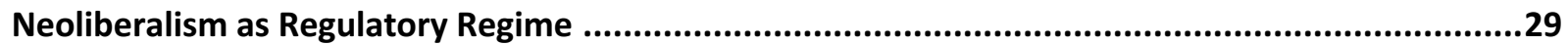

Changing Nature of Practice: Material Effects of Short-Term Funding ...........................................30

Changing Nature of Practice: Shifting Knowledge Bases and Databases .......................................31

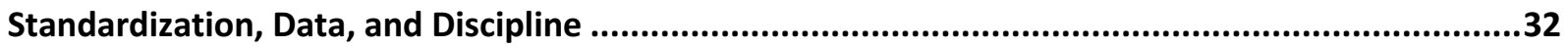

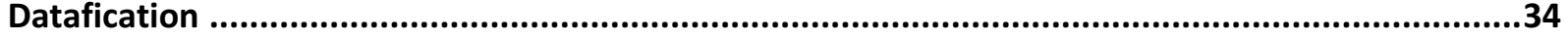

How my Study Fits with the Literature ...........................................................................................37

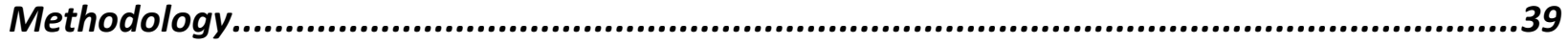

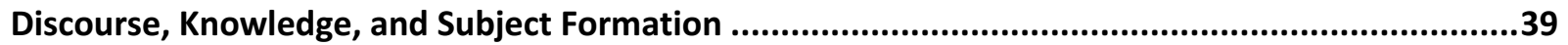

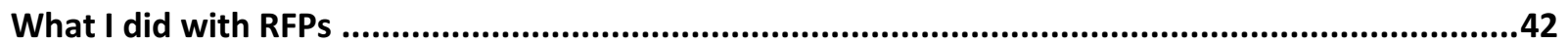

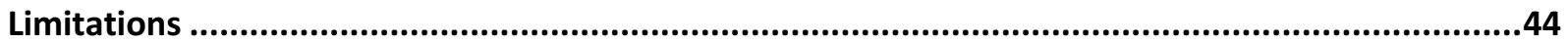

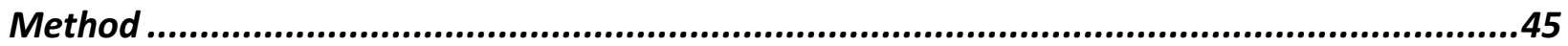

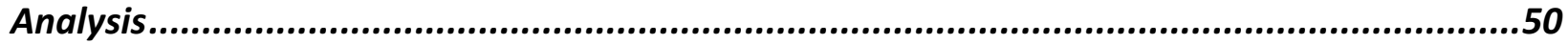

Section 1: RFPs Construct People and Behaviors As Problems to Be Solved....................................50

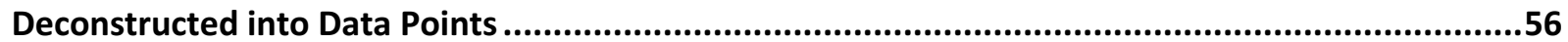

Section 2: The Burden of Applying and Demonstrating Expertise ................................................64

Section 3: Reporting Mechanisms: Normative Data, Governmental Priorities and Understanding Social Issues as a Marketing Problem .............................................................................................70 
Blurred Boundaries: Outreach to Gay and Bisexual Guys Who Use Drugs: Much Like Marketing Shoes ......... 75

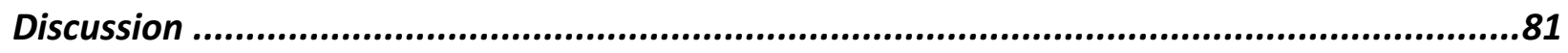

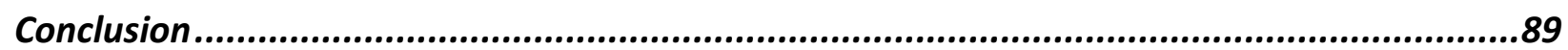

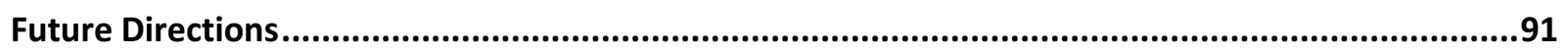

Works Cited:.....................................................................................................99

Appendix A 
List of Appendices

Appendix A: Example of data collection and storage.............................................89 


\section{Introduction.}

This study seeks to understand linear conceptions of time as a structuring variable in a web of relations mediating state funding for community agencies, funding priorities and how social workers work with and understand their clients. My study will ground itself in a discussion of neoliberal restructuring of health and social service provision in Canada. I will also focus on datafication to understand the centrality of data in competitive social service environments where many agencies compete with each other over scarce resources. Linear time, as I will argue, foregrounds discussions of data as it allows for easy data capture and analysis. Datafication must be understood within a context of subject formation as more and more social action is translated into predictive data sets which flow between corporations, the academy and governments (Dijk, 2008). I read datafication with Parton's (2008) conception of Informational Social Work to look for resonances with social work. I analyze short-term Request for Proposals (RFPs) in this study as I am interested in how RFPs construct people and problems, privilege certain knowledges as well as what reporting obligations do to both social workers and clients. My hope is that this study will open up RFPs to social work research as they remain curiously absent from social work literatures as a primary object of investigation.

\section{What is an RFP and why are they important to social work?}

In a blog post explaining the role of applying for funding as an NGO, the charity Imagine Canada explains RFPs as an extension of the public and private granting system in Canada. RFPs act as a completed "bid" to receive funding which are then used for providing services. Grants are made available to organizations at a host of levels (Federal, Provincial, Municipal, etc.) as well as through community foundations and private organizations. They write of the 
granting system by noting that “[e]ssentially, it's money (restricted to certain activities or unrestricted) that could help fund your nonprofit's next big initiative" and that "[m]ost grants typically focus on supporting a particular function or project, rather than an organization as a whole" (Lockett, 2020).

Governments, community foundations and private charities allow organizations to compete for funding through a competitive system of bidding. RFPs are one name given to this process of bidding, where some other names include: Notices of Funding Availability (NOFAs), Request for Applications (RFAs), Funding Opportunity Announcements (FOAs) among others. Bidding as a non-profit for money requires that organizations use a particular structure that then also structures their proposal. The structure of RFPs typically requires "[e]xecutive summaries or abstracts, statement of need, program design or methodology, adequacy of resources, evaluation plan, organization's background/history or organization capability, sustainability statement and/or budget" (Browning, 2014, p. 16). Addressing the process of applying, while also unintentionally signalling an asymmetrical relationship between NGOs and funders, Browning (2014) writes: "[a] proposal is a structured document that must follow each grant maker's specific guidelines" (p. 16).

In other words, grants are important to social work in Canada because that is the primary system by which money is made available to non-profit organizations to run projects while providing compensation to human service workers including social workers. Grants are released by various entities but follow processes that agencies must adhere to in the application process in order to be eligible to receive the funding. RFPs, however, are structuring documents with norms of communication that agencies must follow. The above paragraphs highlight two dynamics that are of interest to this study: 1) grants are generally made available for projects and 
not core operations and 2) each application must follow the guidelines set out by the grant maker. How priorities are set and to what extent agencies are bound up within a dialectic of shifting governmental priorities and changing practice conditions and what that means for both social workers and their clients on the ground is something I will explore further in this essay. One important area worth discussing when considering the granting system in Canada is that of data and what the value of/in data are.

\section{Data and RFPs}

Data is also discussed in the Imagine Canada blog post. Funders, according to the author, like to see and measure your organization's impact in the community it serves by utilizing relevant data in the application process. This implies that organizations are not only actively collecting data but holding on to it for future applications. Data are a form of currency for the funding applicant whereby funders are able to understand the impacts of your practice and ability to satisfy the needs of grants. The blog post author mentions: "[u]sing these figures not only shows the value of your organization, but also your organization's ability to report on the impact made in your community" (Lockett, 2020). She writes further that data really matters in the later part of the grant lifecycle where one needs to demonstrate that: "you spent the money as outlined in your proposal, demonstrating the impact the funding had on your organization's work" (Lockett, 2020).

Data matters in the writing of successful RFPs and in justifying the money one has received. What is unclear from the blog post, however, is who is making data matter as a form of evidence and in what way? If agencies need to follow the grant maker's structure and they want data, then data matters to the funders and not necessarily to the social workers. This 
distinction matters because it means that governments want data for two reasons highlighted above: to measure and then demonstrate impact in the community and also in terms of accountability in being able to adequately run and report on funded projects. But why is this the case? When did data become so valued and how can it communicate both impact and accountability?

\section{Neoliberal governance, NGOs and funding as control}

NGOs grew in Canada as governments retreated from direct service provision while moving into funding them and exercising control over them. There is literature already available outlining the rise of Non-Governmental Organizations (NGOs) in Canada beginning in about the 1970s. The growth of the sector accompanied the government's divestment in directly providing services. The government moved from provider of services to funder where funding levels are arbitrary indicating that the move out of providing services was also a form of austerity. For example, since the 1970s, funding to the women's sector in British Columbia (BC) consistently receives a majority of public funding in the province. However, funding at times has either remained the same or shrunk based on who is in power rather than demonstrated need for services (Clement, 2019).

At the Federal level, control over how funding is delivered, and what can be done with it is, at points, similarly arbitrary and asymmetrical. Under Stephen Harper's Conservative government, many public advocacy and research NGOs were made ineligible for funding with the introduction of a rule outlining a maximum of $10 \%$ of NGO funded time could be put towards 'advocacy' (Knight and Rodgers, 2012). At the same time, 12 out of 16 regional offices of the Status of Women Canada were shut down due to budget cuts. Knight and Rodgers (2012) 
contend that the budget cuts and changes to eligibility criteria for NGOs applying for Federal funding were explicit attacks on feminist NGOs where research and advocacy took up a significant portion of their activities.

The government, in other words, is invested in the working lives of social workers and the organizations they work for. I say this because on one hand, the government enacted significant forms of control over how social workers practiced, while at the same time, increasingly downloaded service provision to NGOs that emerged in Canada alongside state divestment. Social workers who at previous points worked directly for the government began working at NGOs where the government still directed how they practiced but from afar. I think this reveals a conceptual contradiction in neoliberal governance: that the state divests itself from interfering in the economy while still exercising control over the lives of people participating in newly created markets through less obvious means.

\section{Grants are increasingly short-term}

In Canada, core funding is increasingly replaced by short-term and contract-based employment where agencies are mandated to run in an increasingly business-like fashion and compete with each over scarce resources. One of the impacts of short-term funding is that agencies find it difficult to maintain staff especially in economically deprived areas the agencies serve (Silver, 2016). Gibson, O'Donnell and Rideout (2007) refer to this as The Project Funding Regime whereby project funding becomes the dominant funding model in health and social services replacing core or operations funding. They say this shift has further increased state control over community agencies in terms of how they provide services by arbitrarily restricting previously funded activities with little to no consultation as an example, further limit advocacy, 
control who and how agencies prioritize clients. Increased control over agency affairs also works to redirect agency time away from their clients and towards the government in meeting increasingly complex reporting obligations.

\section{How Linear Time is Understood in this Essay.}

I will seek to understand linear time as background factor, or structuring variable facilitating the rise of short-term RFPs and the turn to informational or datafied social work. To show this, I triangulate larger political forces in this essay by reading short-term RFPs as my primary object of study. I hope to make the case that time is continuously being linearized thus making possible and intensifying many of the forces shaping contemporary social work practice as described in the literature. Linear time, for example, sets the stage for short-term RFPs in that fundable projects are written to be accomplished in a short amount of time - sometimes as little as six months. Projects, as I will make clear in the proceeding sections, are broken down into constitutive parts essentially describing projects on an imaginary timeline from how to understand a particular social problem, to reporting, to the desired therapeutic goals, and how programs are to be counted and when. How problems are understood and how to solve them as another example, which I also make clear in my analysis, utilize data to stand-in for decision making processes and promote particular discourses about people and what they deserve.

\section{Why study short-term RFPs?}

I study short-term RFPs in this essay because, as I have briefly touched on above, shortterm or project specific funding along with an increasing reliance on data is the norm in social work practice. Short-term RFPs will be knowable to social work practioners as well as social 
work researchers. Short-term RFPs sit at multiple intersecting junctions of power and potential resistance making them vital and interesting objects of study to consider within multiple discourses of power, subject formation, control and social work practice. They are documents which reflect power relations in that they are written to be enacted in communities. The way they are written, however, is normative in that they construct people and social problems as worthy of agency and social worker investment. They select for some problems as being worthy of attention while inherently ignore others.

My interest in this topic is also inspired by the work I have done in the field where I began to ask questions of why I was doing the things I was doing and what else I might have done with the time. I have spent so much time doing data-entry where each software I was reporting to required me to enter data in particular and sometimes different ways; and which I never felt adequately accounted for the person I was working with or for. Much of my time was spent applying to grants with totals sometimes as little as $\$ 5,000$ - $\$ 10,000$ with little to no community consultation because there was simply no time.

Additionally, much of my time was spent translating what I knew community members wanted into funding areas, which never neatly overlapped. It is this ethically ambiguous aspect of my experiences in the field that served as the starting point for me to interrogate concepts of control, time and data through this research. I want to ground my analysis, the longest I have ever attempted, in material which is directly accessible to multiple audiences because it forms the material basis of social workers' working lives, is of concern to social work academics and validates those frustrated and rebellious clients who taught me more about ethical practice than any clinician's guide ever could. I am also a frequent service user and I have been that frustrated and rebellious client. It's a good place to be; I highly recommend it. 


\section{Theoretical framework}

\section{Biopolitics, imperatives of healing and empowerment, and social intervention as control}

In the following section, I hope to articulate how RFPs act as enabling texts connected to multiple interests. RFPs are written to be translated into projects which allow for particular kinds of activities while disallowing others. A dynamic of encouraging particular ways of working with people while not concretely disallowing others suggested to me that I need a theoretical orientation to reading which helps facilitate an understanding of this process. To that end, I use biopower in this section as I want to understand RFPs as reflecting multiple power centres directing subject formation along with social workers whose working lives are intimately bound up with utilizing RFPS in the construction, running, and reporting on projects.

This section will seek to address the ways in which RFPs produce projects which shape how people live. Specifically, I will use the concept of Biopower (Million, 2013; Cruikshank, 1999; cf. Foucault, 1990) to read RFPs. Following Foucault, Million offers a description of Biopower as being heavily intertwined with the management of people's reproductive potential while also defining and redefining what constitutes a problem. She writes that Biopower "refers to any state's interest at managing the biological potential of a 'population"' and involving the need to "identify and then defend categories of purity and worthiness" (p. 44). Biopower helps explain how RFPs connect to state interests and how particular people are opened up to government involvement while others are not.

The concept of biopower enables me to expand the reach of my study while exploring RFPs in a fuller and more interdisciplinary way. RFPs sit at multiple junctions of poweracademia, the state, social work, and data infrastructures - reflecting multiple centres. Biopower, as a concept, helps to explain, for example, why certain interventional approaches are 
favored and why. RFPs articulate the goals the government has for managed populations (that X amount of people learn to manage $\mathrm{Y}$ issue in $\mathrm{Z}$ timeframe for example) which also stipulate the conditions under which social workers practice (that X intervention be used to help manage $\mathrm{Y}$ problem in X timeframe) and report on progress. The government's articulated goals for particular populations through the granting process changes how we as social workers understand and work with clients. In dictating the conditions underlying social work practice, the government also exerts a form of control onto the lives of people who access services.

I want to make a quick note on my language choices in this section and the rest of the essay. Biopolitics as a theory helps me understand social life as a set of processes connected to particular goals reflecting multiple power centres. The theory speaks to a contextual relationship between power and subject formation. To that end, I want to use words which reflect the processes I write about. For example, I am curious why some people are provided opportunities to negotiate how they are conceptualized and why some people are provided much less space. When I articulate processes exploring how people are understood in this essay which I believe happen 'from above' (for example, how governments release RFPs explaining the problems people face without providing opportunities for those populations to engage in those processes of definition) I refer to them as taking place "from above." With this word choice I want to emphasize how power is concentrating over matters of definition which has a relationship with how people are subsequently produced and managed.

When I refer to people as "vulnerablized," as an additional example, I want to emphasize the ways in which vulnerabilities are not innate to people, but rather, produced and managed in society. As I will explain in detail throughout this essay, RFPs construct people through definitions which on one hand open them up to funding and services, while on the other detail 
how those services might increase surveillance, or data extraction, or encountering social workers etc. Additionally, I will explore below how some people under biopolitical regimes of management are opened up to structural violences (Million, 2013).

\section{Million, Cruikshank and biopolitical management of people}

Biopower refers to how governments manage biological potential of populations (Million, 2013; Cruikshank, 1999) as an extension of the state's power to administer and optimize the conditions of life at both the individual and population levels which became tied to encomic processes in the $19^{\text {th }}$ century (Foucault, 1990 a )and facilitates a deeper understanding of the way in which RFPs structure social interventions to facilitate the production of selfgoverning subjects who can appropriately manage their own affairs. It also helps us understand why certain people or specific subcultures are targeted in the granting process over others. I will explore this below by looking to Dion Million who helps tie biopolitical governance with the rise of psychology, specifically self-actualization and the need to "heal" in an Indigenous context. I will also look to Barbara Cruikshank's work addressing the role of empowerment as a means of getting people to self-govern with a focus on poverty. I use these two authors because they make sense to me as a social worker who has written grants for mental health and community development programming and practiced in both areas. I also use them because healing and empowerment straddle psychological and sociological knowledge bases which constitute the majority of theoretical tools social workers draw from both presently and in the recent past when designing interventions and in understanding how social problems and personal troubles interrelate (Parton, 2008). 
Biopower, according to Dian Million's (2013) reading of Foucault, concerns any state's attempt at controlling a population's productive potential. By this she means the ways in which governments intervene in the social word in such as a way as to produce the means by which people will willingly choose productive forms of life over others. In order for people to choose particular lifeways, however, work needs to be done to frame some ways of living as problems. From this perspective, the state attempts to understand and intervene in the lives of people to "defend categories of purity and worthiness, categories understood in the most intimate of terms" (p. 44). Put differently by Cruikshank (1999), biopower seeks to import the good life onto those understood as deviant or other. The creation of a category by the government, for example poverty, opens it up to being acted on, quantified, and turned into a problem thus bringing it into the realm by which a liberal government can intervene. She writes: "[s]olutions to the problems of poverty and need can be tried out only after the problem of poverty is transformed into a set of possible actions. For example, to declare a war on poverty, drugs, or garbage is to say that these fields are open to action, places upon which it is possible to act, and where government might intervene" (p. 40).

Cruikshank (1999) argues that the idea of citizenship itself flows from particular investments by the state to infuse self-hood with ideas and practices favourable to liberal capitalist ideals of self-management and accountability. The outcomes of biopower are not the repression of subjectivities, but rather, a proliferation of 'ways of being.' Lifeways, however, are not neutral or natural. People are, for example, provided services to learn to 'help themselves' (Million, 2013, pp. 40-42) meaning that people learn skills to manage themselves through the programs social workers apply to run in the community. As one set of skills are 
learned, older ones are inevitably displaced and so there is no neutral mode of living in this mode of analysis.

Important for both Cruikshank and Million is that although governments are invested in the management of people, power is dispersed throughout the social arena where the state's power is more concentrated in some contexts (consider police, courts and prisons for example) and more diffuse in others (regulations allowing mental health providers to keep people detained in mental health hospitals against their will). Power is contextual in this reading where the state intermingles with different power centres.

Biopower's first concrete articulation was found in linking particular qualities to particular kinds of people in order to ascertain their worthiness and conversely, help explain their deviance. The first category produced under this new style of management was that of poverty in $19^{\text {th }}$ century Europe (Million, 2013, p. 44). Because particular qualities were highlighted as being embedded in people, governments opened up areas of life as places appropriate for knowledge production and social intervention. The government first needs to create a problem which cuts across society as a threat, thus providing a justification as to why they are able to act on it. Categorization also leads to quantification as new people are brought into categories which work through comparison and binaries. People, through this process, learn to compare themselves to an imaginary statistical and moral norm. For Million, this partially explains the rise of everyday practices such as assessments. People are taught to assess and manage themselves which partially work through comparison and binaries (worthy/unworthy for example). Biopower also works to grant the state a kind of consent in enabling certain actors to correct the actions, thoughts, behaviors of particular groups understood as deviant as a means to have them adopt lifeways which are by contrast, statistically and morally normal and healthy. 
Million (2013) turns to Nikolas Rose in order to understand the rise of psychology as a discourse imparting practices of biopolitical self-governance. Million is concerned with settler colonialism, Indigenous self-governance from above and below, and the imperative to heal. However, her discussion of psychology and contemporary notions of "healing" are useful for my study. For Million, in an extension of Rose's work, the psychological sciences are of particular prominence in contemporary regimes of biopolitical governance as they provide a knowledge base that is useful for producing workers who use tools to control their affect and comportment. Of interest for Rose is that the psychological sciences impart assessments as the means by which people turn inwards and work on the damaged parts of their psyche and thus 'heal' from their pasts where one must “continuously manage one's own emotional and mental hygiene" (cited in Million, 2013, p. 150).

Psychology is useful to that end because when practiced, it provides people with the tools of 'actualizing themselves.' In other words, psychology is helpful in that it provides people with the tools to continuously monitor and assess their interiority in order to root out malady and heal from it. This wouldn't necessarily work if there was not someone for people to compare themselves to, and work on themselves for, which is why it is significant that it is psychology which invented the statistical and morally 'normal' person. It is this imagined normal person who is infused with an ethic of self-management and capacity for self-regulation to which people are taught to compare themselves (Million, 2013, p. 151).

For those who are suspect in their capacities to be autonomous, like Indigenous people are for Million's work (2013), a conceptual knot is revealed. Indigenous people are granted resources by their inability to 'self-manage' while also opened up to death and malady by being at-fault for their inability to 'self-manage.' Indigenous people are, to Million: “subjects of 
concern for their ability to self-control, to be autonomous, to be happy, well-adjusted members of a free society where one monitors one's own behavior.” (p. 151). Thus, they require interventions from above, the kind psychology can provide, along with the imperative to 'heal' from their past in order to be proper capitalist subjects. However, because they are constructed as being suspect in terms of their capacity to be free, self-regulating and healthy, they are also responsible for their own demise (p. 151). It is the dual movement of being worthy of intervention on the one hand, while responsible for their own material conditions which opens them up to culpability on the other that I find interesting in tandem with the discussion of the prominence of psychology in relationship to biopolitical control. Psychology provides ample tools by which the state might semi-constantly assess the 'progress' of certain groups through funding while also allowing greater access to those communities for further study and open them up for death should they not make 'proper' use of the resources granted to them. This process turns colonization into a psychological problem and so renders it a-historical.

I am interested in the idea that I might be able to read social interventions and RFPs as a kind of litmus test of social citizenship. In the case of neoliberal capitalism, one's place in the good life is tied to one's ability to be a self-governing, accountable, and economically productive person. I want to again emphasize the dual-nature of governmental intervention as both productive and coercive because it would read semi-hollow if the goal of biopower were simply to have people elect lifeways which correspond to social norms. It is also about opening people whose bodies, minds, and/or actions fail to conform to violence, sickness and/or death, which I think also serves a pedagogical aim in the lesson of autonomy: that if one doesn't elect to contort themselves to the available options, however constrained, they deserve to fail. Social interventions, in that sense, are always carrot and stick; a kind of citizenship test that is on-going 
which can be found in RFPs via their articulation of social problems connected to certain groups of people and expected outcomes. But the values which infuse citizenship change and so it makes sense then that the goals of funding also change which change the concepts social workers use to identify problems as well as the practices social workers use when in community.

Million helps me understand how psychology individualizes social phenomena and treats poverty caused by colonialism in Indigenous communities for example as a problem with brain chemistry rather than a structural one; a past event which requires individuals to commit to heal from 'old wounds.' While the academic discipline of psychology might produce knowledge about particular problems, professional psychologists and social workers turn them into actionable programs to be used by people in order to heal themselves. As a worldview, discipline, and form of treatment, the products of psychology are shown to be copacetic with the values of liberal capitalist societies and so complement each other. One of the ways they are copacetic is that they both strike me as profoundly a-historical. What is caused and maintained structurally is individualized to problems in emotional and affective regulation which the individual needs to seek out programs for in order to learn to adjust to systemic harm. Structures are maintained while people are taught to treat their minds and bodies as problems which furthers the projects of liberalism and capitalism as opposed to challenging it.

For Million, the political question surrounds the imperative to heal from trauma as an Indigenous peoples where that healing does not further reify the state. For Cruikshank, her interest is in empowerment with a focus on poverty. On empowerment, Cruikshank (1999) notes the wide array of actors settling on empowerment as a solution to political problems. She notes how both the right and the left leverage the concept of empowerment along with its opposite, disempowerment, as a kind of panacea for social problems. Where for the right, the goal of 
empowerment is one of increasing economic participation, to the left, the goal of empowerment leverages political education to help people transform the systems they rely on. To Cruikshank, the point is not to assess which interpretation is correct, she personally agrees with the left-wing analysis, but that empowerment is an order of discourse which further reifies the state through interventions that promote self-governance. All programs of empowerment seek to transform those understood to be disempowered in order for them to redirect their energy. She writes: "[w]hether inspired by the market or by the promise of self-government and autonomy, the object of empowerment is to act upon another's interests and desires in order to conduct their actions toward an appropriate end; thus "empowerment" is itself a power relationship..."(p. 69).

For me, what I take to be significant in Million's and Cruikshank's work is that they directly interrogate the terms social workers use on an everyday basis (empowerment and healing for example) as neutral and show how they are in fact implicated within regimes of subject formation and social control. It also helps me understand how the words we use do not appear for no reason; rather they appear in the grants we apply for, the books we read, and so on. We interact with these terms, words, and concepts on an everyday basis and internalize them without reflecting on their history. Of interest in this study is looking at RFPs as texts which instruct as much as they dictate in that they provide useful information explaining how social workers come into a knowledge base (that the word 'empowerment' is associated with particular kinds of outcomes for example). Furthermore, changes in the words found in RFPs can instruct social work academics to a potentially shifting ideological and funding landscape as it relates to what the state wants from peoples' life choices and what they think the value of such interventions are. 
It is important to pay attention to the range of actors who are exercising a power over people as both Million and Cruikshank make clear. For Million, the psychological sciences include both academics and practicing psychologists and social workers who are enacting a kind of subject creation through actualizing the imperative to heal. For Cruikshank, it is the ways that empowerment functions as an instructive tool to assist people to become politically engaged and thus enter politics: "[t] echnologies of citizenship — the organizer's "issue campaign," the radical's "revolutionary consciousness," the social worker's "plan for self-sufficiency," the social scientist's "theory of power," the neoconservative's "empowerment zone," the feminist's "selfesteem" - all seek to mobilize and maximize the subjectivities of those perceived to lack the power, hope, consciousness, and initiative to act on behalf of their own interests" (p. 71).

One point made by Cruikshank that I find to be particularly interesting concerns state action and the economy. It has already been explored in this section that the function of biopower is not merely to constrain people but to enable them to live in particular ways that are conducive to liberal and capitalist frameworks; yet Cruikshank also explores how biopolitics or state action works to secure capitalism. One might think of capitalism as a natural economic phenomenon that requires no maintenance by the state. Or one might think that liberal democratic governments and capitalist systems are naturally copacetic with each other. In reality, though, both are made where the state acts in such a way as to get people to elect lifeways that are in line with the needs of the market. In other words, social interventions might be understood as a means by which people deemed potentially outside the workforce can be brought into it. Cruikshank (1999) writes of social intervention (including social workers): "[i]ntervention and prevention work as a kind of recruitment. Even when an economic rationality is brought to bear on a social problem (drug addicts must be made over into self-governing 
agents in order to spare the state the expense of foster care and treating drug-addicted infants), its method is to govern people by getting them to govern themselves" (p. 39).

Power in my view is located in multiple centres and locations but which all act on particular people who are of interest to the state by way of their non-normativity. Although my study will focus on RFPs, one needs to read them in an almost 'pastiche-like' way reflecting multiple interests rather than in a strictly top-down manner. Control over categories involves multiple actors, for example, who have different reason for why they want a term to mean particular things. It is not fair, in this view, to read RFPs as purely emanating from the state even though government agencies produce and release the RFPs. It's important to read RFPs expansively in order to situate them within their proper historical context and necessitates I read them alongside theory in order to broaden my understanding of what they mean, and what they do to people including social workers. This context includes: the wording of the grant, the projects being funded, how they are reported on and refined by the same government departments among others. Discourse analysis (and see below for further discussion) and biopolitics make sense in the reading of RFPs because RFPs reflect multiple actors: social workers, agencies, government departments, academics, particular styles or modalities of providing care, communities and individuals. Biopower helps clarify several aspects of RFPs, namely why RFPs make problems out of certain actions, thoughts, and/or behaviors along with how people are supposed to 'fix' them. How one comes to be understood as non-normative necessitates a broad reading practice that can account for such a multiplicity of actors.

Reading RFPs through biopower helps me understand why certain interventions are privileged over others through the granting process. For example, it might make sense of why RFPs favor projects which select for certain kinds of behavior modifications, teach particular 
kinds of practices (like self-awareness, or self-care, or distress tolerance) and/or borrow from certain theoretical traditions. It might also explain why some grants (likely in community development contexts for example) speak to community empowerment and others to psychological phenomenon like trauma. It also helps me understand why data figures so heavily in the granting process as data is knowledge production. For example, some RFPs will make mention of certain communities who are available for funding, such as those that live in poverty. Other RFPs make mention of specific behaviors reflective of certain subcultures further distinguishing people from communities for example a focus on substance use among gay men. How this focus becomes identified is through data collection, which allows for fine distinctions to be made between people. It is possible that more specific references to subcultures reflect higher orders of discourse that refract even finer attributes, which come to be known to the government through data collection, analysis, and reporting. Data reporting software (as I will explore in my literature review) also standardize the ways in which grants are reported on and discipline social workers into running projects in a unfiorm way partially to make data collection more coherent and simple. 


\section{Literature Review}

\section{Neoliberal Restructuring of Health and Social Service Provision in Canada}

Neoliberalism in Canada transformed how governments manage community organizations. Provincial governments took an active interest in shaping the structure of community organizations, how they provided services and to whom as they exited from direct service provision. Multiple experiments in local service planning and provision took place in British Columbia during the 1960s and early 1970s. Social planners were inspired by the 1970 Commission on Emotional and Learning Disorders in Children (CELDIC) which argued that: “...services needed to be decentralized to neighbourhoods, coordinated and integrated through the community service centre model, and held locally accountable through community management..." (Clague, 1997, p. 92). Services needed to be accountable to communities by being managed by them. This insight resulted in the emergence of Community Resource Boards (CRBs) whose role was to assess community priorities and advise the provincial government on allocating funding to community organizations in order to address them. CRBs outside of Vancouver were empowered by the province in taking responsibility for planning non-statutory social services (p. 96).

The province took the CRB model even further in Vancouver by establishing the Vancouver Regional Board (VRB) which was responsible for planning and partially funding non-statutory and some statutory social services. For a brief time, the VRB even took over responsibility for welfare provision (p. 96). The VRB was comprised of neighbourhood CRBs where representatives were elected in municipal elections. The VRB, unlike other CRBs, was tasked with directly providing money to neighbourhood CRBs in meeting local health and social service needs so long as they met provincial goals of preventative health spending (pp. 96-97). 
Community work's status grew alongside CRBs and were empowered by the province to do so. Experiments in local health and social service planning saw the province mandate local decision making by empowering communities through funding and sometimes deferring to them. The CRB and VRB model lies in contrast with the downloading of service provision onto cities and NGOs which came to British Columbia in 1975 with the election of the Social Credit Party and further intensifying in the following decades (pp. 99-102).

In 1983, the government recentralized its responsibility for health and social service planning and provision in order to semi-privatize it. The justification for recentralization was partly bolstered by an emerging ideology of family and community responsibility for matters of welfare. Declining revenues from natural resources partially justified the Provincial government in cancelling the CRBs and creating the Ministry of Human Resources (MHC) in its place. Ministry of finance directives at the time revealed new ideological frames for understanding health and social service provision arguing that: “...where possible government...[intended] to give the private sector the opportunity to take over functions and activities not appropriate to government" (p. 100) During the 1980s, funding for health and social services was increasingly earmarked for non-governmental organizations in the form of short-term contracts which greatly increased NGO penetration throughout British Columbian society (p. 104) but without the organizational structure, community accountability and scope of the CRBs. Organizations were beholden to governmental but not necessarily community priorities. Community development funding during the 1980s and 90s was almost exclusively earmarked for community economic development (p. 104) representing a diminished scope of practice.

Changes in health and social service provision in British Columbia beginning in the 1980s saw the government end its experiments with local planning by wrestling political control 
from the local level in order to partially divest from direct service planning and provision. Empowering the growth of the NGO sector but without the CRB's organizational and community mandate also meant that the government had effectively renegotiated its understanding of who is responsible for providing social welfare. These changes also show how governments shape community practice to be in line with their policy agendas.

The restricting of funds to health and social care in British Columbia in the 1980s follows a similar trajectory to changes made at the national level beginning around the same time. During the 1980s, the Federal government began freezing and reducing Canada Assistance Plan (CAP) payments to the provinces. The CAP consisted of a funding arrangement made between the Federal government and the provinces to share the costs associated with health and social services. Passed in 1966, CAP funds assisted provincial governments in providing a number of important services including higher education, health care (Bryant et al., 2011) and welfare. The federal government under CAP split the costs of service provision at 50 percent up to a certain threshold. The federal government under CAP matched provincial funding for particular programs meaning that $\mathrm{CAP}$ funds came with stipulations to which the provinces had to agree (Herd, 2002). Federal contributions to the provinces under CAP began to decline in the 1980s "forcing retrenchment in many social programs" (Bryant, 2009 as cited in Bryant et al., 2011, p. 51) leading to its eventual cancellation by the Liberal government in 1995 . Shortly after, the Canada Health and Social Transfer (CHST) was introduced. The CHST disaggregated funding to the provinces meaning that unlike CAP, funding provided through the CHST was not tied to certain programs or services. The CHST allowed provinces to experiment with social safety nets and its introduction facilitated the first workfare requirements in Ontario along with excluding 
particular people from receiving welfare, something the CAP specifically disallowed (Herd, 2002, pp. 106-107).

The Canada Health and Social Transfer (CHST) saw the federal government reduce its financial contributions to the provinces affecting the availability of health and social services. Changes in levels of funding provided to the provinces intersected with an emergent philosophy of market-based solutions to questions of welfare. In the aftermath of the federal government downloading more of the costs associated with social care onto the provinces, the provinces downloaded costs onto municipalities (Dunlop, 2019). Municipalities are less capable of generating revenue than provinces or the federal government, so downloaded services were either cut, left unfunded or privatized. Around this time, market logics of competition and corporate governance structures were increasingly introduced into social service provision and corporate management styles were implemented in the social policy realm (Beresford, 2005, P. 468). These changes affected the governance of community organizations, how they access funding, the quality of contracts awarded, and how organizations report on funding.

\section{Neoliberalism as Regulatory Regime}

Neoliberalism is also a regulatory regime producing particular kinds of self-sufficient people. One important aspect of neoliberalism-as-regulatory regime is not that the state fully withdraws from the social realm but rather redirects where and how it invests itself in order to encourage the production of particular kinds of people. Brown and Baker (2013) argue in the United Kingdom (UK), beginning in the late 1990s, social citizenship was imbued with an ethos of self-reliance and responsibility justifying a suite of government interventions aimed at correcting anti-social (here understood as conditions perceived as being antithetical to personal 
responsibility and economic participation) beliefs, actions or ideas. They list the regulation of live music in cities, bills criminalizing begging, and forcing people receiving state benefits to seek jobs as examples. In so doing, citizenship under neoliberalism is shown to be moral as opposed to a-moral as neoliberal governments claim about matters of the econmy (pp. 14-15). The transformation of the meaning ascribed to social citizenship can also be shown in how governments fund community programming and what goals are prioritized.

Ledwith (2013) writes that in the UK, funding to organizations actually rose with the election of the Labour government in 1997 but where the funding was overwhelmingly shortterm in nature, specifically funded organizations to address "anti-social behavior", encouraged economic participation and mandated skills-based approaches to practice (pp. 23-28). What this means is that funding levels to community services can increase and still promote neoliberalism. In other words, funding alone is insufficient in telling you about the ideology of particular governments. The better question is found in asking what the funding does, or how it is to be enacted along with which ideologies are expressed through it, rather than how much or little of it there is.

\section{Changing Nature of Practice: Material Effects of Short-Term Funding}

As core funding is continuously replaced by project-specific funding, agencies find more of their time goes to managing money and reporting to donors. Jim Silver (2018) conducted interviews with several community organizations serving Winnipeg's inner city (a conglomerate of several downtown wards) trying to understand the city's persistent racialized poverty. One Executive Director (ED) interviewed stated that she found it nearly impossible to spend time in the community she served because she was reporting to over 40 funders a year (p. 135-136). 
Many of the organizations Silver studied stated that project-specific funding made it difficult to retain staff from the communities they served as they could not guarantee secure and decent employment (pp. 136-137). The shift to project-specific funding also emphasizes the importance of data as data provides the rationale and justification for funding including meeting state standards and benchmarks (Noonan, Sabel \& Simon, 2009).

\section{Changing Nature of Practice: Shifting Knowledge Bases and Databases}

Parton (2006) cites Samuel (2005) in suggesting that the nature of social work practice has changed showing a third of social workers interviewed spent more time doing administrative work about their clients than directly serving them (Samuel, 2005 as cited in Parton, 2006). Shifts in how social workers spent their time correlated to the widespread adoption of common standards and assessments relying on communications technologies (p.262) corresponding to social workers being able to better make people "knowable, calculable administrative "subjects" (Parton, 2006, p. 258). Beginning in the 1990s, Parton contends that managers of social service organizations started to supersede front line social workers as the primary intermediaries between multiple social institutions. Managerialism facilitated a new ethos of social work practice: standardization. Standardization and the communications technologies facilitating it effectively transformed social work from a profession concerned with relationships to a profession concerned with information. 'Relationships' here doesn't mean inherently good, though, where the presence of a social worker can be violent and the relationship extractive. Parton describes this transformation as swapping the why with the what in social work practice (p.259). The psychological and sociological theories social workers were taught to actualize with their clients in order to understand individuals within their context became less important 
than noting and classifying behaviors in order to note differences and outcomes. To Parton, this change signified that social work practice had come to greater reflect the tools and techniques of managerialism (pp. 259-260).

The data entry practices used by social workers are beholden to operating systems which allow for only specified inputs and outputs: "rather than be concerned with presenting a picture of the subject, as, previously, social work increasingly acts to take subjects apart and then reassembles them according to the requirements of the database" (Parton, 2006, p. 263). The same standardized assessments and data entry practices produce knowledge about people in the aggregate and through loose categories that Cheney-Lippold (2017) argues have no epistemological foundation; meaning that definitions change as new data sets are continuously added, sorted and compared (p. 147). As a result, quantitative data about people is generated and then used by governments in a top-down fashion producing them in the process. Individual people are deconstructed via particular data points and then reconstructed via standardized inputs (Hall, Parton, Peckover and White, 2010) and are "strategically fictionalized" (Cheney-Lippold, 2017, p. 41) back into narratival identities such as "at-risk" which changes how they are understood by workers and clients themselves with material consequences for clients.

\section{Standardization, Data, and Discipline}

Data is key to the implementation of an "accountability culture" generating selfgoverning subjects afraid of violating standards (Roberts-Holmes and Bradbury, 2016, pp. 601602), which has ramifications for both social workers and the communities they serve. In order to understand changes to social work in Canada, it is useful to draw from examples found in the literature from the UK and Sweden. These examples are helpful in order to understand some of 
the implications of social work's increasing dependence on standardized forms of practice and how they were implemented. The common assessment tool used by child welfare workers in the UK differentiates between the "objective" needs of children and the "subjective" concern of practitioners. During the early stages of its implementation, practitioners were told not to record insights gleaned through interaction or practice knowledge as it was not derived from evidencebased frameworks while the needs of children as found in the assessment and defined by the government were (Hall, Parton, Peckover and White, 2010, P. 403).

The English government disciplined child welfare workers into using the common assessment by downplaying the validity of experiential knowledge. At least in the UK, social workers are increasingly becoming social administrators instead of workers where practice knowledge is politicized as subjective, and social problems are rhetorically framed as technical problems to be solved through evidence-based practice models produced by governments. Evidence-based practice is understood as neutral and scientific (Trinder, 2000, p. 9) and therefore free of politics and better able to predict behavior even if the nature of social work practice is changing to include generating large swaths of data about vulnerable people.

The rhetoric utilized by the UK government in the above paragraph turns social problems into technical problems and trains social workers to become administrators of assessments and metrics. Standardized assessments are made real through communications technologies which depend on particular inputs and, to carry on with my above example, transform children into units of concern. When taken in the aggregate, we can more easily see how information and communication technologies (ICTs) and standard assessments turn individual children into "children" as an imagined category. The change I highlighted is significant in that it takes individual children out of their material contexts in order to facilitate an understanding of 
"children" as a collection of behaviors and actions made sense of from above. The government, in other words, is implicated in the discursive production of people which in turn changes how people think of themselves, their actions, beliefs, and behaviors; it makes them governable subjects.

Beginning in 2006, the government of Sweden produced the BBIC (The Child's Needs in Focus in English) and began implementing it across the country where it slowly became the dominant framework for understanding how to assess children. The goal was to “...get a uniform system that can also be used to collect and evaluate information in a systematic way" (Ponnert and Johansson, 2018, p. 2028). Standardization in the health and social service fields is also important in so far as it helps in the collection, storage and assessment of data. For example, the drive towards standardization of assessments in Sweden was pushed forward partly to compare individual children across large data sets. This process is helped through standardizing the information individual child welfare workers provide, making such an analysis simple and consistent over time. But why the Swedish government standardized the kinds of data to be selected for by every child protection worker is made easier to understand by focusing on what van Dijk (2014) calls Datafication.

\section{Datafication}

Governments want the projects they fund to provide data showing they were able to meet the goals of the funding. However, what does data do to people? What are the ideas which make the capture, storage and use of data seem desirable? How are areas of social life opened up to quantification? Jose van Dijk (2014), extending the approach in Mayer-Schoenberger and Cruikier (2013), argues that datafication is driven by the epistemologically faulty promise of 
objectively translating social action into data points in order to predict future behaviour. She claims that this kind of data and analysis over-privileges the objectivity of the information gathered because people 'freely' provide it when accessing services such as social media and email clients for example. The idea is that because people provide the information they do in an unpromoted or coerced fashion, the data is more objective than other forms of collection. She refers to this belief as Dataism which describes both the belief in the predictive potential of metadata capture, analysis and storage as well as a large degree of unearned trust the public has when handing over large swaths of datapoints to corporations and other institutions including government agencies.

Datafication blurs the boundaries between commerce and forms of service provision including healthcare which many people assume to be outside the market. Ruckenstein and Schüll (2017) argue that as categories such as health become increasingly datafied, they also move between spaces now bound together through their reliance on capturing, storing and analyzing and selling large swaths of data representing ever finer elements of human action. They note that corporations such as Nike sell consumer data from fitness tracking devices to marketers, insurers, tech firms (such as 23 And Me) who in turn sell aggregated data sets to pharmaceutical companies and medical device makers. Ruckenstein and Schüll say further that: "[p]atient data is valuable also to advertisers, insurance companies wishing to conduct costbenefit analyses, credit-rating agencies wishing to create richer consumer profiles, and hospitals wishing to improve facility efficiency and save costs or to calculate predictive "health and frailty scores" for their patients" (p. 263).

As data increasingly stands-in for objective decision-making processes, concrete and material outcomes flow out of an inherently unstable form of knowledge production. It is at the 
point at which data does not reflect but direct processes (such as how someone scales on a 'frailty' score which itself emerges as a product of multiple data sets for example) where the connection to biopower becomes clearer in the construction of identities. For example, to what extent does one's assumed frailty come to calculate one's deservedness in being able to access services and supports and what does this signal about the norms governing who is the proper recipient of care and who is conversely exposed to sickness and/or potential death? This process is inherently from above and might mimic similar processes described in the preceding section around the construction of common assessments understood through datapoints and percentages as opposed to conversation and engagement.

Blouin (2020) argues that large datasets perform objectivity in the assemblage of health data at the point at which datasets become evidence for doing something with it or when data becomes evidence. Specifically, he says that as databases convert large swaths of particular data points and present them as evidence for policy, programs and/or interventions, databases reflect both presence/absence and are implicated in the curated production of knowledge (p. 319). Databases present curated knowledges as empirical evidence where the background work of selecting some information while negating others is often invisiblized. The presence of a curated data set is made legible by 'invisibilizing' or obscuring those data points which complicate or are not made a priority for selection criteria by whoever is purchasing it. He writes: "[d]ata silences, blind spots or the absence of data speak of the ignored, the excluded, and the unwanted as much as the "key indicators" reveal a prioritization process." (p. 321). Who or what is prioritized, therefore, is never a neutral phenomenon and has implications for social workers who often work from government agencies prioritizing programs focusing on particular traits, vulnerabilities, 
problems etc. Data informs such choices but data is also far from being as objective or as predictive as people believe.

Governments want the "vulnerabilities" they prioritize to be reduced through the interventions they fund as well as ensuring accountability in how organizations run programs. Government Request for Proposals (RFP) ask community organizations to provide data supporting their funding requests, along with project timelines, expected milestones, and to what extent the vulnerabilities identified will be ameliorated. This process is sometimes referred to as "impact investing" whereby organizations are expected to efficiently utilize money to generate the most impact for the people being served (Arvidson \& Lyon, 2013). Impact investing fits into what is also sometimes referred to as "accounting" whereby social workers are asked to be increasingly accountable to the funding they manage and connects to a larger neoliberal philosophy of "efficiency" extending further into areas of social care (Chow, Greatbatch and Bracci, 2019, P. 1583). As I have already described above, neoliberal governments are interested in shaping how community organizations operate. Data production, data input, and reporting 'cherry-pick' specific qualities of people to measure, including, as an example, aspects of behavior. Therefore, community organizations are increasingly reliant on project-specific funding that asks organizations to meet specific targets while utilizing specific reporting mechanisms that make use of specific kinds of data inputs.

\section{How my Study Fits with the Literature}

My proposed study will look to see how conceptions of linear time as a structuring variable, as background enabling the rise of datafied or informational social work and its connections to the production of data and knowledge about people. The databases social 
workers increasingly utilize reduce people to qualities, behavioural attributes, and categories which are easy to input/output and importantly work within comparative assessments and analysis (Parton, 2008). Linear timescales allow for data to be more easily collected from the beginning to the end of a project showing impact. This means that linearity becomes an important tool for generating knowable subjects over time.

This phenomenon is networked in a social service landscape that is increasingly reliant on short-term interventions, which depend on pre-defined categories of success in order to be eligible for funding and future funding. Communities are increasingly quantified, therefore, potentially made legible to the government through the running of community projects. As I have said above, governments construct notions of people from above, which can potentially change how those people understand themselves in the process. Social workers ultimately run such projects in the community and are therefore important actors in constructing vulnerable people in ways that reduce them to the inputs and outputs that governments wish to measure and track. This connects to the loss of the relational in social work practice along with broader changes affecting health and social service delivery in Canada resulting from the neoliberal turn in the 1980s. My research builds from Park's (2008) assertion that: “[a]lthough the concept of social construction of identities has become a part of the social work lexicon, studies of the mechanisms of identity construction-examinations of the ontological foundations and epistemological frames that define the profession's work—remain rare in the field" (Park, 2008, P. 773).

To that extent, my paper will begin with a close reading of RFPs as my object of study as a means to understand broader changes in social work practice. I will look to see how RFPs construct people and problems, privilege certain knowledges, as well as what reporting 
obligations $d o$ to the field of social work practice. My hope is that this study will open up RFPs to social work research as they remain curiously absent from social work literatures as a primary object of investigation. RFPs are in many ways the face of government funding as they are the documents which enable organizations who mediate both state and community. They are also written for organizations to apply to receive and so should provide context as to many of the changes I have described above.

\section{Methodology}

\section{Discourse, Knowledge, and Subject Formation}

I will be utilizing discourse analysis to elucidate the ways in which government RFPs both understand and construct community members through the imposition of linear time onto community organizations. The study of discourse is the study of statements which "follow the principle of dispersion and redistribution" (Garrity, 2010, p. 201) and are formulated along with other statements producing discursive formations and knowledge (Garrity, 2010, p. 201; Foucault, 2002). Discourses are expressed through language and other mediums including objects, enunciative modalities (including language), concepts and strategies producing groupings of statements which speak to particular things and people. Discourse is essentially a social practice in that it is something we do. One does not merely speak about things, but rather, one occupies a particular viewpoint or discourse from which they then speak (Garrity, 2010, pp. 201 - 203; Foucault, 2002). If we inhabit discourses, but do not "author" them, we "take a discourse on" and then make claims about the social world furthering their proliferation or dispersion.

To Garrity (2010), the objects of discursive formations are not internally coherent, and their meanings shift over time and laterally across various institutional contexts (p. 203). This 
means that while many helping professions are able to speak to a category such as the "client" (for example) in different institutional contexts, its meaning can change based on which social space the speaker is located. Discursive formations are fluid and intersect with other existing discourses sometimes producing what appears to be internal coherence. Consensus over a definition materializes power relations leading to control over the uses of the category and limits the number of speakers who are able to talk about it (Jäger. 2001, p. 35). Consensus over the definition of a discursive formation is always contingent to a moment in which particular discursive objects or categories "emerge or are transformed" where its meaning is formed in between discursive fragments (Garrity, 2010, p. 203; Jäger, 2001, p. 41).

The term "client" as a social category (to keep with my previous example) appears static and coherent in that one can study "clients" and speak about "clients" at social work conferences but it is not. Social workers and the institutions legitimizing social work as a profession exert control over the "client" as a category along with what kinds of knowledges can be produced about the concept. Control over the category constructs the client as an empirical phenomenon that can be researched and both produces and reproduces the client to be understood at the population level (Jäger, 2001, p. 35). The endurance of the category as an empirical phenomenon also materializes the client as controllable via granting systems speaking about them and their needs while naturalizing such a discourse in other discourses such as academic literature. The client exists as a category understood from the top-down which depends on a tapestry of relations producing the client in a social context and in a subjugated position (Foucault, 1990, p. 140-142 b). The endurance of the client as a category does not reflect objective truth about the category. Rather, the concept's definition is undergoing microscopic 
changes and challenges in the different contexts under which the category is evoked, by whom and in what setting(s) and over time.

Who gets to speak truthfully about particular people, practices and beliefs while being believed is often a product of a-symmetrical power relations. Discourses allow particular people to inhabit positions of authority meaning they are allowed to speak on behalf of others (Garrity, 2010, p. 204). That people can inhabit roles of "knower" and/or "known about" concerns subject formation and hierarchy insofar as those who are relatively disempowered are usually inhibited from narrating back from their social position (van Dijk, 2008) or prescribed particular places from which that kind of narration is made possible or fought for by communities. This means that discourse constructs social environments which constrain what can be said at any given moment and by whom. Discourses similarly produce people within hierarchies.

One can imagine a social worker and their client. If the social worker has a belief about what is motivating their client's actions or thoughts, they are generally allowed to investigate and report on them. It is likely that the social worker's hypothesis will be believed over and above their client's because the social worker inhabits a role which allows them to make claims about their client's inner and outer worlds. The case notes of social workers reflect the idea that social workers are privileged knowers over and above their clients because case notes are written in the third person (Munro and Hardie, 2018, p. 412) effectively disappearing references to intersubjective forms of knowledge (p. 413). Through an analysis of discourse, one can better appreciate the ways in which case notes, for example, are institutional apparatuses facilitating social workers' claims to expert knowledge about their clients.

Discourses construct subjectivities insofar as they do not describe people, but rather “constitute particular modes of power" by which people come to understand themselves and 
inhabit potentially unequal subject positions in the world (Park, 2008, p. 773). How groups are categorized, by whom, and why this is important to how one is categorized contains the possibilities of stigmatization which can be internalized (Jhulia and Abrams, 2011, p. 279) thus grounding inequality and material deprivation (Park, 2008, P. 773). How identities are understood, produced and categorized takes on a different meaning as it concerns social workers, however, as: "social work is inherently concerned with intervening and changing clients and their lives" (Juhlia and Abrams, 2011, p. 279). Social workers might perpetuate the same privileged discourses producing vulnerablized communities through the processes we utilize in practice. This includes the granting process when social workers contribute to, or utilize fictionalized narratives produced through data-rich stories produced from above such as classifying someone as "at-risk" via particular behavioral score-card or assessment.

To Garrity (2010), the value of discourse analysis in social work research is that: "discourse analysis can...provide a fruitful methodology from which the exploration and analysis of normative discourses is possible. In this way, it can be an aid in mapping and understanding social phenomena through exposing the formation of social practices, behaviours and subjects" ( p. 208).

\section{What I did with RFPs}

I asked questions of RFPs in my analysis that I logged in a word document which I have attached as 'Appendix A: Example of analysis and storage. The geographical areas accounted for in this study are: (1) RFP from Nova Scotia, (2) RFPs from the Federal government available to organizations across Canada, (1) RFP from Victoria, BC, (1) RFP from Toronto, Ontario (2) RFPs from Ottawa, Ontario, and (1) RFP from an organization based in Toronto running an 
Ontario-wide campaign. The different levels of government accounted for in this study are: (2) RFPs at the Federal level, (2) RFPs at the provincial level, (4) RFPs at the municipal level and (1) RFP from a Toronto Non-Profit running a province-wide campaign.

RFPs are interesting and useful in the same way they are challenging and difficult to work with. RFPs are vital primary documents to read for they sit at a juncture between state, community organizations, other actors and people. They tell stories about people, populations and the problems they face. They are in every way living and normalizing documents in that they are written to be actualized by organizations into programs which are meant to 'serve' people but only in very particular ways; their wording constrains as much as it allows in the sense that they negate by their very wording particular kinds of programs and sometimes particular groups of people from receiving services. Because RFPs are constructed as almost technical documents, interpretation is challenging because much of the political content needs to be inferred. RFPs are top-down documents in that they are authoritatively written while often making claims about people without citation. Only some of the RFPs I surveyed contained anything approaching a reasonable justification as to their existence. They are written to dictate as much as possible to organizations who then turn the wording into action in the form of projects. In this sense, RFPs are clear attempts by the government at getting to know particular people, populations, and/or problems better via mandatory reporting mechanisms.

This does not mean however, that social workers, community organizations or communities themselves are passive players in a top-down form of datafied subject formation. Much work has been done detailing how social workers subvert neoliberalization of health and social service provision. For example, social workers resist the alienation of neoliberal social service work through unionizing in greater numbers than other kinds of workers (Baines, 2010). 
Social workers and community members can produce new understandings of each other based on a shared understanding of their political situation as is the case with peer models of mental health support in a unionized social service workplace (Carniol, 1990).

\section{Limitations}

The geographical areas accounted for in this study are: (1) RFP from Nova Scotia, (2) RFPs from the Federal government available to organizations across Canada, (1) RFP from Victoria, BC, (1) RFP from Toronto, Ontario (2) RFPs from Ottawa, Ontario, and (1) RFP from an organization based in Toronto running an Ontario-wide campaign. The different levels of government accounted for in this study are: (2) RFPs at the Federal level, (2) RFPs at the provincial level, (4) RFPs at the municipal level and (1) RFP from a Toronto Non-Profit running a province-wide campaign.

One limitation of this study is that although I survey a large geographical area, my study does not cover some geographic areas such as the prairies, The North, much of Atlantic Canada and Quebec. My analysis misses densely populated cities like Montreal and Vancouver as well as rural locations. The method I use does not easily lend itself to reproducibility nor are the results reflective of the sample sizes commonly needed for generalizability. I do not interview social service workers, nor do I interview government workers who are responsible for funding decisions. The purpose of this research is to begin a conversation that hopefully others may find to be interesting enough to consider making use of RFPs in the future. In this sense, this essay is exploratory in nature by proposing an avenue by which RFPs can be made useful for future research. 


\section{Method}

I will be using discourse analysis as a tool to read RFPs to get a better sense of how they construct people and problems, legitimize particular knowledges in the application process along with reporting mechanisms to better understand linear time's role as a precondition for the amassing of data about people and communities. Discourse analysis is an appropriate method to employ for this study because it facilitates a greater appreciation for what the wording in RFPs do to people. How discourses set discursive limits in regard to populations (like that of the client for example) partially determines what can be said about them, justifies interventions done to them, and also delegitimizes their resistance as potentially incoherent (Dijk, 2008, p. 10). This means that although the wording of RFPs might be made to sound neutral and objective, they are alive and produce social reality (Jäger, 2001, p.36), which includes unequal subject positions (Wodak and Meyer, 2001).

I analyzed 8 short-term RFPs in a Canadian context to see how different short-term projects structure the kinds of projects social workers work on in particular communities. I looked at RFPs for questions which address conceptions of time in the running of a project, as well as questions about data collection which depend on, or are made easier through conceptions of linear time. For example, if a question asks to collect participant self-reporting at the beginning and end of each session, I will include it as the project is standardizing how time is allocated. This is significant in so far as the expectation of data collection is mandated as well as situating it within a linear conception of time in order to compare participant outcomes. I note the presence of questions in each of the RFPs around determining need for a project, project descriptions, project timelines, milestones, data collection and specificities on reporting. I ask three sets of interconnected questions of each RFP including sub-questions. I then log questions 
and answers in a word document in order to keep my data stored in one location to make it easier to count, display and utilize in my results. I ask two types of questions: open-ended questions which involve description and closed-ended questions involving either yes or no and/or counting.

The first set of questions I explore centres discourse and subjectivity. In particular, I am looking to see how people are talked about, by who and justified through which knowledges. For example, I note when populations are talked about via the actions or behaviors RFPs seek to address through community programming. It is important to look at this aspect of RFPs as discourse is grounded in concrete material processes connected to both social action, the construction of identities and domination (Fairclough, 2001, p. 122). This is important because the wording of RFPs frame aspects of people's lives as problematic and in need of correcting while contracting community organizations to carry the project out.

I also explore how RFPs make reference to how need was determined and if communities were consulted in determining the need. This question helps to reveal how power is organized and who is empowered to make expert judgments about particular groups of people and grant organizations money to solve them. These questions will hopefully elucidate how power is enacted through the discourses located in RFPs as an arena of social action; ultimately the wording of RFPs is to be enacted onto community through the production of a project. The ways in which RFPs describe people, put them into narrative form and frame them as problems needing to be solved is ultimately what the first set of questions will seek to uncover.

The second set of questions I am asking concerns the way in which projects are framed by RFPs and the kinds of supporting documentation one is required to provide should they apply. I am interested in this line of questioning because how time is structured in the submission process partially determines the scope of the project as well as delineating what is not. For example, if a 
project timeline needs to be submitted in order to receive funding, the project's scope is already partially determined before the project is even initiated and potentially before communities are consulted.

I am also interested in the ways in which the submission process asks applicants to demonstrate expertise in order to receive funding. I am interested in this because I am looking to see how expertise is proved. Which kind of supporting evidence is provided corresponds to orders of discourse legitimating certain actors and practices marking RFPs as normative documents legitimating particular kinds of expertise (quantitative, behavioral etc.) over others (collaborative, community driven, qualitative etc.) in supporting an organization's claim that they are best suited for the contract (Fairclough, 2001, p. 124).

The third set of questions I am asking concern reporting obligations for agencies or organizations in the running of the project. I am interested in these questions because they structure the work organizations are being contracted to do. The quantity of reporting as well as quality of reporting is changing the nature of social work practice (for example the move to tracking behaviors in reporting software). How agencies are being asked to report on their project also changes how they might run the project or interact with clients. I am asking these questions to get at how time is standardized in the wording of RFPs and how governments utilize the data they are requiring social workers to collect.

\section{1) How does the RFP describe the population or behavior?}

A) Is a population or populations described via problems or problematic behavior(s) that require agency attention?

- If yes, describe. 
B) Is the problem or problems split into multiple or overlapping syndemic factors?

C) Is the problem or problems presented in the RFP supported by data or references to data?

D) Does the RFP make reference to previous projects in describing an approach they want organizations to take when working with a population or addressing a behavior?

- If yes, describe.

E) Is the population, populations or problem or problems referenced requiring attention justified in relation to government or agency priority (strategic plans for example). - If yes, describe.

F) Does the RFP contain a description of whether or not the particular communities have asked for an intervention or been consulted?

- If yes, describe.

G) How many times do the words "risk," "risk reduction," "risky behavior," "at-risk," "high-risk," "risks," "risky," "risk-taking," "disadvantaged," "disadvantage," vulnerable" and "marginalized" appear in the RFP?

\section{2) The proposed project}

A) Does the RFP ask for a project timeline to be submitted in the application?

- Does it further specify to include milestones or particular markers of success?

- If so, describe.

B) Does the RFP ask agencies to apply with examples of prior work experience in a related project, working with a particular population or demonstrate certain knowledges? 
- $\quad$ If yes, describe.

\section{3) Reporting obligations}

A) Does the RFP outline certain deliverables?

- If so, describe them.

B) Will the deliverables need to be supported through data?

- If it's not obvious, can you infer?

- If so, describe them. 


\begin{abstract}
Analysis
My analysis reflects my process of reading RFPs in a systematic but generous way. I say this because RFPs are challenging to read and contain multiple discourses which makes them inherently fragmentary texts even if assembled to be read in a coherent way. The process I describe in the following section is written linearly as a process flowing from governments onto organizations and then onto communities themselves although the process I am grasping at in this study in actuality is likely not like this. I want to foreground my analysis in the idea that I am telling a particularly one-sided story and in so doing perhaps not living the argument I attempt to articulate because I want to highlight how governments act on people. I do this partly for expediency and partly for making this thesis useful for my own political projects. In my own political work I have seen first-hand that governments and people are mutually influencing. This is all to say that capturing the complexity of how RFPs 'objectively' structure social service provision is very difficult and probably impossible. I am suggesting only one entry point through this essay as I try to make the point that RFPs are of-interest for social work scholars and social workers in understanding the processes which might be partially responsible for the continued degradation of the social safety net, the making of anti-social social work cultures and produce harm to the people we serve as practioners.
\end{abstract}

\title{
Section 1: RFPs Construct People and Behaviors As Problems to Be Solved
}

My research shows three broad ways RFPs construct people and/or behaviors as problems: 1) RFPs construct people as problems based on what they do or are likely to do; 2) 
RFPs construct people as problems based on what they do not have enough of, and 3) RFPs construct people as problems based on what they do not do but should. I explore these themes below via an exploration of the "background' or 'context' session.

This section covers the ways in which the government instructs social workers to deconstruct clients into datapoints that reflect the desired goals of the RFP. The main arguments I make in this section are that short-term RFPs individualize social problems, leverage data to tell stories about people, and constrain how social workers work with clients which connects to how data is collected and reported on. Linear time features in the section as an enabling force in the background. For example, the projects are all time-limited meaning that the scope of the project is already largely constructed along with the kinds of data which can be collected to fit within such a framework. The grant dictates the terms of engagement and not community. Because the projects are largely determined from above, however, this connects to a larger strategy of neoliberal biopolitical governance in the creation of knowable subjects who are being taught to work on themselves.

RFPs construct people and behaviors as problems that require intervention in a number of ways. The first and most obvious concerns the use of 'background' or 'context' sessions explaining the rationale for the pot of funding being made available. Such background sections are interesting in that they are written authoritatively and often make use of citations in explaining sometimes contradictory but data-permeated stories about people. A 2021 Ottawa city government 'Paint it Up! Youth Engagement Mural Project' RFP focuses on providing "youth who are at-risk or are already tagging" opportunities to paint murals in their communities as opposed to "tagging" their communities. The RFP makes its case for the problems of graffiti, where: 
The impacts of graffiti on the community are numerous. Graffiti can reduce the community's pride and appeal, have a negative economic impact and negatively affect the community's perception of safety and security. If left unchecked, graffiti spreads rapidly and leads to a phenomenon known as 'Broken Window' Syndrome where people feel like nobody cares, and nobody is in control” leading to increases in crime

Graffiti or tagging is contrasted with 'art', which does not contribute to broken windows syndrome. Youth, in this grant, are to be trained to become 'artists' and not 'taggers' through an intervention which seeks to 'empower' them by diverting them away from behaviors which increase crime and gang activity and towards activities which do the opposite. The claims about the power of art are articulated via a complex set of effects it can have for communities. A host of disconnected ideas are somehow made tangible and therefore desirable through the production of art and the active deterring of tagging. The RFP claims that:

Transforming graffiti-covered walls into brightly-coloured works of art can completely change the feelings and the outlook for residents and business owners, as well as tourists," and that, "Graffiti vandals usually respect art, so they generally don't tag it. Outdoor murals have proven to be effective in managing graffiti vandalism, enhancing beautification, supporting arts and culture, contributing to economic development, and providing youth engagement opportunities

The background section makes no claim as to what art is, or what graffiti is for that matter, but through tying tagging to crime, "youth at-risk or are already tagging" distinguishes those youth who make their communities safe from those who do not and justifies an 
intervention in the process. Youth who make graffiti contribute to the breakdown of their communities while youth who 'paint murals' make their communities more beautiful and better.

The broken windows theory is used to justify an intervention regardless of research suggesting that police appropriated graffiti into broken windows theory to empower themselves in 'controlling' behaviors stemming from communities understood in the popular imagination as 'uncontrollable' (Bloch, 2020). A ten-year study of broken windows policing in New York City found that it resulted in greater police presence in marginalized neighbourhoods and greater numbers of charges for misdemeanor crimes including vandalism in specifically Black and brown communities where Black people accounted for over 50 percent of arrests (Kamalu and Onyeozili, 2019). The Paint It Up! RFP selectively cites for a background section which justifies more intervention into particular communities themselves likely racialized and overpoliced. Additionally, at the completion of the mural, Ottawa Police Services must be invited to attend effectively introducing police services to communities they may not be familiar with.

Other background or context sections do similar kinds of discursive work cleaving particular people or traits into focus and telling stories about them that justify interventions based on what people do not do but should. A 2021 City of Ottawa Community Economic Development Funding program prioritizes programs which work to provide "job creation, business creation, entrepreneurship skills development, employability skills development" including soft-skills training for members of particular communities including geographic and identity-based communities. Applications will score better if programs are "geared to disadvantaged populations (e.g. "lower income youth and older adults, rural residents, new immigrants, visible minorities" etc.), while also demonstrating social justice and inclusion, and /or cultural diversification benefits" but with no other explanation. To omit explanation as to 
why so many are economically disadvantaged while also listing so many different types of people hides structural factors which might help illuminate economic disparities between people. The curious grouping of people into those labeled as "disadvantaged" reifies economic inequality by naturalizing it to something about them, something internal which inhibits them from doing what 'good' citizens do: paid work in the formal economy. This RFP reifies structural inequity through a grant which seeks to build employment opportunities for "economically disadvantaged" people as if the problem with joblessness is merely being without a job. The wording lays the blame for unemployment on those who are unemployed.

Some background sections distinguish people as being worthy of intervention because of what they do not have. A 2020 Toronto Urban Health Foundation (TUHF) - Child and Youth Resiliency Stream RFP supported by the City of Toronto makes the case for funding projects which seek to change the behavioral patterns of "high-risk children and youth with the aim of preventing or delaying the onset of risky behaviors such as substance use and unsafe sex" through promoting resiliency which they apparently do not have in sufficient quantity. The RFP argues that approved projects must utilize the City's resiliency framework in order to be eligible for funding where "resilience refers to the ability of individuals to cope successfully in the face of stressful or risky situations as well as the ability to 'bounce back' from difficulties they encounter." The framework argues that youth "with a high number of developmental assets are more likely to engage in constructive activities (e.g., school success, demonstrate leadership, maintain good health), and less likely to engage in risky behaviors (e.g., substance use, school problems, violence)." The concern is that the cumulative effects of risky behaviors leads to a range of mental and physical health outcomes which are problematic from the perspective of public health: 
These outcomes include physical and mental health issues, violence and other aggressive behaviors, and adjustment problems in the family, school and workplace. Health and social issues include unplanned pregnancies, transmission of STI's (including HIV), emotional and social trauma, substance use, and injuries and death related to alcohol/other drug use

Although evidence is cited as to why this list of behaviors can be grouped together as symptoms of a problem - i.e. the RFP's focus on resilience - it remains unclear as to why all of the above behaviors are caused by a lack of resiliency alone.

Paul Garrett (2016) charts the rise of resiliency theory in academic social work during the 1980s to argue that it became dominant under an economic ideology of austerity where resilience has since become neoliberal governments' "...panacea for managing social problems.” (p. 1916). Garrett elaborates further by arguing the connection between resilience and neoliberal social policy by highlighting how resilience is primarily concerned with providing people the means by which they can accurately govern themselves where each person is “....responsible for the accumulation and maintenance of individualized forms of human capital” (p. 1919). Garrett notes that this is why the resilience literature (particularly from psychology) pays special attention to childhood (p. 1914).

It is clearer now as to why the behaviors listed as problems in the TUHF RFP are problems. Substance use is of concern to the government for example, because it takes away from a productive adult's capacity to accrue and maintain social and economic capital. In essence, a lack of resilience is a problem because it prevents one from becoming a good and productive worker, which is akin to one's cost of entry into citizenship (Cruikshank, 1999). The focus on interventions building appropriate levels of resilience in children and youth is to assist 
them in developing the necessary disposition to effectively participate in the economy later in life. The wording in the THUF RFP argues for resilience as the sole attribute worth promoting over and above other forms of interventions which perhaps might serve children and youth better but at the cost of their imagined productivity later in life where good citizens bend themselves to the needs of the economy and not the other way around.

\section{Deconstructed into Data Points}

While there are broad themes in how RFPs work to justify interventions, all of the RFPs I surveyed rely on singling out qualities which read like data points in a spreadsheet of social problems. The ways in which RFPs tell stories about people and communities work to deconstruct them via particular empirical inputs (behaviors, actions, group identities etc.) that through interventions spaced out over time, generate data that correspond to the goals outlined by government. Importantly, these goals become the goals of organizations through a granting system which asks NGOs to adopt the government's approaches and goals as if it were their own; agencies, in a sense, mirror governmental strategies and practices blurring distinctions between the government and the providers of services. The blurring of lines between government and social service agencies reflects a project the government - at least hypothetically - divested responsibility from having any stake in since the neoliberal turn in the 80's and 90's. For example, the TUHF RFP makes specific kinds of interventions available for working with children and youth in order to fast-track the development of appropriate levels of resilience which is the goal of the government. Of the four acceptable interventions, one of them is labelled "normative education" which "involves providing children and youth with a more accurate picture of the prevalence of sexual and substance use activities to counter their 
perception that smoking, drinking, sex, and the use of alcohol/drugs are normative behaviors for their age."

The RFP provides no additional context as to why normative education is a good choice of intervention to use, or why subjecting youth to binaries of normal/abnormal is an ethical choice for organizations to make on behalf of the communities they serve. The TUHF RFP, in other words, mandates psychologizing frameworks for working with children and youth who are arguably made vulnerable by a host of structural conditions rather than just psychological structures. It has made choices which negate the practice knowledge of child and youth workers and makes no reference as to whether any children and youth were consulted and stated that they want these kinds of interventions. What is important to the TUHF is that which can be easily measured where structures of power and oppression, although always at-play in the lives of children and youth, are too difficult to pin down and track. Childhood and youth, in the wording of this RFP, are knowable through behaviors which are easy to track.

It echoes the move to top-down and mandated forms of working with people that I described in a previous chapter around the disciplining of child and youth workers in the UK to accept an algorithmic understanding of childhood vulnerability (Hall, Parton, Peckover and White, 2010). This echoes Parton's (2008) contention that social work practice is now informational in character and more concerned with managing large swathes of data sets. The THUF RFP is framed from above, where the desired outcomes are set for organizations, where data reporting practices are tailored to be in-line with areas the government wishes to see progress on.

To some extent, I wonder if alternative projects or visions for service provision could be articulated and funded within a context of short-term RFPs. I wonder to what extent short-term 
funding also grinds certain approaches of understanding both social problems and their available solutions into everyday knowledge. For example, to fully test out an idea might require funding to merely engage with youth in a fulsome and good-faith way, to explore available literatures for evidence, to facilitate organizational diversity as it concerns strategies for working with youth which work within an organization's locality. If funding only lasts two years, I wonder whether that possibility and diversity is cut short and conformity to the state's proposed solutions are adopted so that organizations are able to receive some funding because providing some services is likely better than providing no services.

This short-term reality facilitates the repositioning of social workers as data workers where managing large swaths of data is increasingly the norm. The requirements of data - often reflected in the language of short-term RFPs - shape how social workers understand clients in an almost algorithmic fashion: as reduceable to datapoints, inputs, and outputs to be measured over time.

What makes this process relatively top-down is that the outcomes of the RFP are set and - at least in relation to the TUHF grant - so are the ways social workers are supposed to work with actual children and youth. My concern is that this level of specificity might negate a more wholistic process of engagement and program development that is less linear although perhaps more complex to report on with the frameworks TUHF is asking for. What if, for example, children and youth, after much consultation, decide they are not actually looking to change their behaviors but wanted programming nonetheless? What if the programming they want is not fundable? Or not fundable in the way they need? What if the data children and youth consented to providing does not relate to what TUHF is asking to be measured? These inherently relational 
elements of practice cannot be negotiated with an RFP because they are written to allow for only particular things and produce particular kinds of outcomes and people.

A 2021 City of Victoria Strategic Plan grant mirrors the TUHF grant in the way it individualizes social problems and the goals they want operationalized in meeting them. Organizations are encouraged to apply to this RFP if they are working towards projects that complement the priorities found in the city's most recent strategic plan. Some of the strategic plan's goals group social problems under categories such as "affordable housing" with one of the measurable targets under it being to "decrease the total number of homeless people." Work is done in this grant to tie homelessness to the lack of affordable housing which is arguably only its most visible symptom. There are many contributing factors to homelessness of which a lack of affordable housing is an incredibly important one but not looking at other structural factors limits the kinds of work that one can do about it. This would be true but less forceful of a critique there was any mention in the RFP of new housing coming online or plans for future housing etc.

For example, the city makes no claims as to what they mean by affordability, or that any new subsidized housing will be built. Rather, they list measurable outcomes related to addressing affordable housing as being to:

quadruple the number of 'Missing Middle' housing units, increase number of co-op housing units, increase in rental apartment and housing vacancy rates, increase the percentage of Victoria residents who own their own homes, and that Victoria is seen as developer friendly.

These outcomes will supposedly address their ultimate goal of seeing a "decrease in number of people spending more than 30 percent of income on housing and a decrease in homelessness." What percentage of people is left unspecified. The interesting part of this grant 
to me is the way disparate things are tied together and counted as measurable instances of creating affordable housing. For example, what is the connection between home ownership and the production of affordable housing? And how is that related to Victoria still remaining “developer friendly?" I would also like to suggest that if Victoria wants to be understood as developer friendly, part of that equation must be in keeping development profitable which to me seems antithetical to some of the ways affordable housing is understood as affordable because the government intervenes in the housing market to take units out of it or construct units which never make it onto the market.

While the Victoria City Council invests in the optics of building affordable housing, while not building any new units, metrics are put forward which are to be counted as evidence of its creation while at the same time signalling who matters in the city's poverty reduction goals. For example, home ownership is put forward as a countable measure of poverty reduction. Why would home ownership be counted as creating affordable housing while building and running affordable housing is not? One entry point in understanding this discourse is if it is read as a strategy keeping the city out of the housing business while still arguing that it is invested in a meaningful set of programs geared at poverty reduction through economic participation. In other words, it is a strategy of neoliberal governance and responsibilized subject formation. It is inherently depoliticizing and allows homeless people to be counted in their barest form: their presence/absence allowing for very simple comparisons, where middle class and wealthy people are to be counted in much more nuanced ways because they are proper citizens. Their grant reflects such a process as well: reducing problems to a countable form while at the same time burying an ideological reason for not engaging with broader policy goals or analyses. 
The desire for people to own their homes as a means to decrease poverty, for example, is a particular policy strategy of neoliberal economic governance premised on the idea that people who own their own homes will have more options in terms of leveraging it should they need to. It is also a neoliberal idea in the sense that it encourages people to enter the housing market and use the value of their house to reduce their 'dependence on the government for support.' In the 1980s and 1990s, governments in the west began to liberalize the mortgage market allowing more low-income people to access mortgages in order to purchase homes. A policy of liberalization also produced a housing bubble where investors turned the likelihood of foreclosures into a financial product to be bought and sold. What marks the 1990s liberalization of the housing market as distinct from other housing programs was that government's interest in people owning their own homes was partially motivated by a logic of austerity and privatization where the government could decrease their involvement in public and economic life (Rolnik, 2013).

From my reading of the City of Victoria's strategic plan, it does not appear as though any new affordable housing is planned to be built. By extension, it does not appear as though affordable housing is actually factored in to the city's analysis regarding which structures produce homelessness. Their measurable outcomes might assist in providing options to certain middle-class people in terms of entering the housing market through the construction of "missing middle" housing units or opportunities to own a home but there does not seem to be any explanation as to how this will translate for those at the bottom. However, what is made clear as it concerns those at the bottom, is the counting strategy the city wants organizations to employ when working with homeless people. The city orients their efforts not to moving people into 
housing units necessarily, but rather counting them in time to see if the overall numbers move. The "movement" is important, and I will analyze that later in this section.

Equally important, however, is that homeless people are reduced to the space they do or do not take up, whereby wealthier people have more robust measures counting more context (where did they move to, did they jump from renter to owner among others). Homeless people are reduced to the most countable or quantifiable variable: their mere presence, ensuring the government owes them as little as possible.

Similar to the TUHF grant, the City of Victoria wants organizations working with homeless people to use their reporting mechanism to demonstrate a reduction in the total number of people sleeping rough in the city. They want social workers to use a "point-in-time count." This type of reporting mechanism makes it easy to argue that the city is meeting its own strategic goals but to what end? Where do the people go? The grant reduces the problem of homelessness to its visibility; where to count fewer of them is to suggest something inherently positive such as that homelessness is decreasing which connects to the idea of linear time structuring interventions, governmental priorities and datafying vulnerablized subjects. However, without being able to work on the myriad factors producing and sustaining homelessness such as colonialism or capitalism or the lack of affordable rental housing, the root causes are ignored. In other words, the grant keeps structures in place and even further erodes the meaning of affordable housing by committing to it as a goal without building any.

Additionally, the city asks for a count of homeless people in time as evidence of them meeting their goal while rendering homeless people informational in the process. The grant quite literally pays organizations to quantify homelessness where the city itself plans on building no housing for them. This connects to the material outcomes of datafication and subjectivity in 
Cheney-Lipold (2017)'s notion of Algorithmic Citizenship. He says that this notion of citizenship is interesting in that it can position one as a non-citizen based on triangulating particular datasets used to determine their "foreignness" which does not depend on their place of birth, but rather, from analyzing their data fragments. These choices include who they send emails to, who they call on the phone, which languages they speak among others (pp.160-164). If we are to imagine micro-citizenship tests as part of the function of RFPs whereby the state allows groups to learn skills necessary for participation in society, it makes more sense why the government would be interested in tracking homeless people in time, while providing them few options in terms of leaving homelessness. The question I have in my mind is one of datafication's material outcomes. If datapoints help determine decision making in the granting process (that $\mathrm{X}$ group of people benefited the most from $\mathrm{Y}$ intervention for example), and potentially determine who counts as a citizen, I wonder if the limited range of options homeless people are provided in this grant is because non-citizenship has already been decided for them. The grant isn't providing homeless people options in the way it is to middle class people and rich people because they have been algorithmically constructed as distinct from society. Homeless people are still managed in society but as people with negligent claims to the social.

Without committing to building affordable units, the wording of the RFP reduces homelessness to a symptom (their presence) in order to more easily turn people without homes into data points to be captured during a point-in-time count while also maintaining the status quo. My contention is that it incentivizes workers to count and shift homeless people around.

Even if people were moved into housing, that might not be constitutive of a progressive solution because unless the affordable housing meets the needs of homeless people, the policy solution still advances precarity. This greatly limits the work that could be done to both 
understand and implement real policy solutions to homelessness based in addressing the factors actually responsible for homelessness. It is clearer to me now that the ways in which the government asks for reporting also works to prioritize projects which reify the state and their agendas.

\section{Section 2: The Burden of Applying and Demonstrating Expertise}

All of the RFPs I surveyed were short-term in length lasting from one to three years where the money ranged from 5,000 dollars to 250,000 dollars. They all asked for projects working towards pre-determined goals and expected outcomes. This means that organizations must match the RFP as opposed to the other way around like the brief experiments in democratic planning under the Vancouver Regional Board I described from Clague (1997). Increasingly agency time is spent applying for and managing grants and some of the RFPs I surveyed had much more onerous requirements in terms of crafting an application than others. How people are to work with communities is constructed from above although significant opportunities for resistance are also always present.

The main argument I make in this section concerns the way in which the burden of applying and demonstrating expertise and knowledge when applying to a project depends on datafied conceptions of objectivity. Essentially data comes to stand-in for objectivity and directs concrete processes which negate other forms of experimentation in providing services. Linear time foregrounds the turn to quantitative data in that there are large datasets being refreshed which are likewise implicated in the production of knowledge and expertise which asks organizations to craft standardized project proposals which are easily comparable to each other. 
Some RFPs ask for supportive letters to be written by experts on issues in their communities. As I note in this section, however, those counted as experts are not always reflective of the populations being applied on behalf of. This connects to my discussion of biopower and my use of discourse analysis in that allowing certain people to make claims on behalf of what communities 'need' assumes some people to have expert knowledge even about communities they might not be a part of.

All of the surveyed RFPs worked to limit the kinds of projects organizations might run by having them meet certain pre-defined expectations in the application of which I go into detail in this section. A 2021 Public Health Agency of Canada (PHAC) - HIV and Hepatis C Community Action Fund asks for organizations to meet certain thresholds in order to be eligible for funding. For example, to apply, an organization must show how need is determined. They list several options: "the rate of infections in the geographic area, relevant factors of transmission, specific trends or challenges you seek to address and the evidence of effectiveness of the proposed approach." How need can be determined is worded in such a way as to maximize the impact of the funding which correlates to a business logic now widely adopted in social service provision (Arvidson and Lyon, 2013).

Categories such as 'impact' and 'trends' and 'need' are thoroughly datafied terms indicating among other things, depths of associations being measured over time. They are processes by which certain terms (understood through the terms PHAC offers to count as evidence of 'need' for example) can be measured through particular indicators acting as standins for other things ('need' being potentially comprised of a host of inputs including physical, mental, cultural among others). The reason this has become increasingly important in successfully applying for grants is that the datafication of everyday life is understood as 
predictive and not merely indicative in that data serves as the material for making predictions about people's future behaviors (Mayer-Schoenberger and Cruikier (2013). The value of datafication partially extends from its description as "non-rivalrous" by economists whereby one's use of data does not negate another's, but rather, becomes richer in terms of its predictive potential when compared (Mayer-Schoenberger and Cruikier 2013, pp. 100-103).

In order for these terms to be datafied, however, they must be standardized and so points to why data production and knowledge production are standardized across RFPs at least in their application and reporting stages. In order for organizations to effectively compete with each other, they must prove their effectiveness in relation to the terms the government wants to see addressed in the proposal. Datafied terms like "population," "effectiveness" and "need" among others lend a sense of objectivity through organizations utilizing quantitative information which cannot necessarily accommodate small or regional experiments when compared to municipal, provincial, and/or national datasets. This is because they are seen as truly objective predictors and so come to count as meaningful in and of themselves while negating other forms of evidence.

In order to secure funding, a number of the RFPs require organizations to show how the intervention is “evidence-based.” PHAC lists several avenues, “...evidence of effective interventions can be shown through: population-based surveys, jurisdiction-specific sources of data (reports focussed on specific key populations or with data disaggregated by populations), research findings and project evaluations." After this, the RFP requires applicants to include an evaluation schedule outlining when data will be gathered, what method(s) will be used, and determining what is changing over time. The RFP mentions that they are looking for both performance targets as well as evaluation targets to be included in the application. Although 
PHAC's requirements were by-far the largest and most complex given the funding was larger, all of the analyzed RFPs included in my analysis ask for similar kinds of leg-work to be done before the project gets off the ground. Every RFP asked for differing explanations of the various projects' timelines showing when milestones would be reached, what each milestone would entail, how it would be traced and when evidence would be gathered before actually crafting the final reporting. This is time-consuming and also primes the applicant - often times a social worker - to think algorithmically about both the program they are applying to run and the kinds of people who will access it. This is because real people with complex needs might need to be sacrificed for a construct, an "ideal fit" which facilitates easy advancement through the program on a linear timeline allowing for easy data analysis, capture and comparison.

To me, this highlights two important aspects of the granting system pushing social work practice towards the informational. The first and most obvious is that applying for many of the RFPs I surveyed are time-intensive prospects which require accessing many types of information to have on-hand about people and the problems they face. Secondly, RFPs structure how organizations apply for funding and what evidence they bring forward to make applications legible. Background work has to be done by organizations in order to begin the application including conducting focus groups to gather information, undertaking needs assessments, reviewing reports and other kinds of tasks (Lockett, 2020). What this ultimately means is uncertain given the limitations of what my study can conclusively demonstrate, however, it does correlate both with the academic literature and the wider professional discourse in myriad articles, books and blog entries concerned with applying for and securing grants. Time, I think, might be increasingly stretched where the tasks associated with grant writing and reporting take up more and more of it and people are, at least, conceptually 'flattened' to better fit the kinds of 
data extractive techniques the government is asking of organizations. Given this observation, one might ask what happens to people who enter a program but are deemed 'too complex' for simple data capture?

RFPs sometimes ask for organizations to demonstrate certain expertise in order to apply. For example, some of the RFPs surveyed arbitrarily require organizations to demonstrate that they have been active for a certain number of years, that some or all of that time has been spent working with the populations they are applying to serve and/or to include special kinds of supporting documents. The 2021 New Horizons Grant put out by Employment and Social Development Canada to fund organizations working with older adults provides an interesting example of mandating that organizations provide supporting documentation along with their application. Much of the interesting content in the request for supporting documentation concerns who is able to provide supportive documentation - and, by contrast, who is not. I argue that this speaks to authority and knowledge creation because some people are able to make claims about the needs of older adults in a particular but not everyone. Who has such an authority might be a position not actually in the hands of older adults but those empowered to know older adults and speak on their behalf. The RFP asks that organizations provide letters of support, but that letters need to come from people who have a specific authority to speak both about the organization and about the needs of the community. They list several possibilities including members of other organizations: "someone from a local Church, an MP, someone from the local golden-age club" etc. They also provide a list of criteria for what constitutes an acceptable letter of support and provide a template: "good letters of support contain: your knowledge and support of the organization, your knowledge and support of the proposed project, the need that will be addressed by the proposed project in your community." 
This is all important in the construction of knowledge, or, who gets to address who as an authority on, in this case, older adults as a category, and likewise, who gets to authoritatively speak about their needs in terms of intervention (Garrity, 2010; Jäger, 2001). The language surrounding who gets to write a letter of support, and what that letter should say, suggests that some opinions are credible while others are less so. Why the letter of support and appeal to expertise becomes a site of interest for this study is that who gets to speak about the goodness of a proposed intervention are not necessarily locatable to older adults themselves but those who are allowed to speak on their behalf. Particular people are trusted with the knowledge of what older adults want, need and who is best to serve them where it might not include any living older adult. It makes sense then that the RFP makes no reference as to whether any older adult was consulted in the creation of the program.

This might be because the "older adult" as a category negates older adults narrating back from their lived position where the wording in the RFP makes it clear they are not necessarily considered a reliable judge of a project's quality where a priest might be for example. I think this is further cemented in how the RFP lists the vulnerabilities associated with older adulthood and how those are reflected in the grant's "national priorities". The government has the data to set the priorities concerning the needs of older adults while empowering organizations to further their agendas and increase their knowledge about them. There is a triangulation in this particular RFP between government, agency and outside authority producing knowledge about older adults, constructing the "older adult" as a category where those actors might constitute some of the discursive strands (Garrity, 2010, p. 203) solidifying the category's apparent coherence.

There are lots of tools available to the government to include older adults, including ensuring a broad range of feedback and guidance from older adults who are also members of the 
particular groups the government seeks to prioritize. For example, there could be a roundtable when the funding pool comes up for review to determine relevance, appropriate scope and priorities the grant should address. In the same way peer positions are built into certain funding requirements, this could extend into any population the government releases funding to serve while paying them for their contribution. Although this leads me away from what I can speak to in this essay, it seems important to highlight that the way things are now could always be otherwise which includes a guarantee to include and pay impacted groups - older adults in this case - in the processes producing grants and social policy about them.

\section{Section 3: Reporting Mechanisms: Normative Data, Governmental Priorities and Understanding Social Issues as a Marketing Problem}

I have to again temper the generalizability of the evidence I provide in the following section because the sample size is low (two RFPs are analyzed as case studies). I chose these RFPs in particular because they highlight two dynamics that are often undertheorized in social work: the first is social workers reporting on social workers and the second is of data acting as a direct line brinigning industry, the government and socal services together. My hypothesis is that the language of RFPs act on community agencies in similar ways that RFPs reorganize how communities are conceptualized by social workers. Data production and datafication factor into this remaking of social services while also blurring sectors of the economy in the process. Datafication connects to informational social work in the sense of changing the knowledge base(s) social workers draw from in order to be more copacetic with the constraints placed on social workers through reporting softwares and databases. 
The two RFPs I highlight are interesting as case studies because they show two themes already identified in the literature and, I think, connect to how data acts on people through reporting. The two RFPs provide examples of: 1) a group being deprioritized for funding and 2) the blurring of different sectors of the economy which in this case refers to government, industry and a community agency. I highlight these two to argue that there might be a relationship between reporting and data.

The 2021 PHAC HIV and Hepatitis C Community Action Fund has different project outcomes based on whether organizations apply for the three or five-year fund. What is interesting in this RFP is that the outcomes change between the "expected outcomes" of receiving three and five year funding in a subtle but I think evocative way. A distinction is made between specific populations (those highlighted in the grant as "prioritized populations") who are most likely to become HIV positive or contract hepatitis $\mathrm{C}$ and those providing services to them (which might include people who have HIV and/or hepatitis $\mathrm{C}$ as well as people who do not). The part I highlight discusses the role of target audiences providing culturally safe and stigmafree provision of Sexually Transmitted Blood Borne Infections (STBBIs) services to best serve the specific needs of prioritized populations. If one receives three-year funding, the expected outcomes of the funding state that:

By 2025, projects supported through the HIV and Hepatitis C Community Action Fund will: increase the knowledge of effective evidence-based HIV, hepatitis C or other sexually transmitted infections (STI) preventions measures among key populations and target audiences. Strengthen the capacity (skills and abilities) of key populations and target audiences to prevent infections and to improve health outcomes relate to STBBI. Strengthen the capacity (skills and abilities) of target audiences to provide culturally safe and stigma-free STBBI prevention, treatment and care services. 
Presumably, the expected outcomes of the funding also shape the kinds of projects which can be run while also providing context as to what will need to be shown through reporting to PHAC. Although this is true for all of the RFPs that I have studied, what is not clear from reading RFPs as one-offs is how reporting works to inform priorities over time. It becomes a little clearer, however, when turning to the outcomes associated with five-year funding of the same grant. The expected outcomes for 2027 are that:

...by 2027, projects supported through the HIV and Hepatitis C Community Action Fund will: increase uptake of effective evidence-based HIV and hepatitis C, or other STI prevention measures among key populations. Improve access to effective STBBI prevention, testing, treatment and ongoing care, and support for key populations. Improve the cultural safety and stigma-free nature of STBBI prevention, testing, treatment and ongoing care, and support services provided by target audiences.

One takeaway is that between 2025 and 2027 the goals have changed slightly from increasing the capacity of service providers in providing culturally safe and stigma-free services to key populations to "improving it". There is a potential judgment made that enough time and funding has been made available to service providers to become culturally competent providers of care at least in terms of their skills and abilities and knowledge of evidence-based prevention. Soon, service providers should reasonably know which evidence-based prevention measures work well for particular populations and what cultural competency is in practice as if it is a static body of knowledge. After 2027, the goal is to increase the uptake of prevention measures by consumers. However, it is interesting that after this time, the needs of service providers slip out 
of focus. It appears that the government will soon assume evidence-based prevention measures as common-sense for service providers, because they will no longer fund training. What appears to me is that the learning needs of services providers are effectively delisted from funding priorities after 2027. Someone had to assess this change in language as being reasonable, and I am curious how data might figure into this decision making.

If funding was being used to train service providers in evidence-based prevention methods, organizations would likely need to be reporting on it. I think it is also reasonable to assume that someone in the government is likewise keeping track of who received cultural competency training around evidence-based preventions methods at least to make a distinction between 2025 and 2027. If service providers are training other service providers and reporting on their training, we might ask whether they report on other service providers in ways that are similar to client reports. This also prompts the question of how data figures into this subtle delisting of fundable activities where, over time, the government has possibly tracked such reporting and then made a decision that a threshold of competency around evidence-based prevention methods has been reached. This may be the justification for delisting further trainings of the kind from the grant. From my research, I speculate that data figures into decision making processes at the state level based on reporting which in this case paints a picture of competency assumed by professional human services workers. Additionally, it then opens workers up to culpability based on an assumption of competency arrived at through reporting. It might be further evidence of data serving to direct how funding is managed. However, more research needs to be done to determine if this is the case.

Similar to target audiences and key populations being on different timelines in the acquisition of knowledge around prevention efforts, so too are service providers in terms of 
achieving cultural safety. Between 2025 and 2027 there is another shift in the language around funding cultural safety training for target audiences. By 2025 work will be done to "strengthen the capacity (skills and abilities) of target audiences to provide culturally safe and stigma-free prevention and treatment..." whereas by 2027 the language has shifted to "improve the cultural safety and stigma-free nature of STBBI-prevention...”. This change in language is important because somehow between 2025 and 2027, according to PHAC, cultural safety and stigma-free service provision will be the norm that requires strengthening, not an ideal being strived for. In my reading, the difference in discourse is important because to "improve" something implies a gap, whereby "to strengthen" something implies a solid foundation where tweeks might need to be made. The "gap," in other words, has been addressed, but how is this decided? Who decided on this being a reasonable timeline?

In order to set a target of some kind (say X amount of doctors will be "culturally safe" providers of STBBI treatment and prevention for their clients) I speculate that some benchmarks must have been set and funding released for projects designed to achieve the goal. It is important to ask how this decision was set and what data was used to assess it. I am curious if not seeing a clear description as to what constitutes cultural safety is prefiguring responsibilisation whereby wording of the grant assumes providers will shortly be culturally safe and knowledgeable on evidence-based prevention methods. I am curious about what it might mean as a social worker to be found not in compliance with 'cultural safety' after 2027 if there is no clear definition provided or training opportunities made available. Although I am not sure what is meant by being a "culturally safe" provider of services, what is interesting is that the word might be working as both a 'carrot and stick' in the sense that the goal is cultural safety which is likely a good thing, but failing to do so becomes one's own fault at a certain point in time and ceases to 
be a the system's responsibility and so people become culpable. This reflects the literature I cite about biopower insofar as social workers might be opening up other social workers to the burdens associated with culpability even if they are unaware they are doing it.

\section{Blurred Boundaries: Outreach to Gay and Bisexual Guys Who Use Drugs: Much Like}

\section{Marketing Shoes}

All of the RFPs I analyzed included that reporting needs to be accounted for in the application process. Although there was variation in how organizations would need to prepare to evaluate their projects, all included some kind of timeline of activities including when evaluation would take place and be reported. Although many of the RFPs did not specifically describe what kind of reporting would need to be completed, given the short nature of the grants, much of the reporting would likely be split into a combination of data points including counting (as is the case with the 'point-in-time count' in the City of Victoria Strategic Plan Grant), knowledge acquisition ('learning new skills' in the case of the HIV and Hepatitis C Community Action Fund) and/or behavioral (as evidenced in the TUHF Child and Youth Resiliency Stream Fund).

A 2017 Gay Men's Sexual Health Alliance (GMSH) RFP repeats what I describe above but also shows something slightly different in the process. For a campaign they are looking to run, the GMSH are seeking marketing and Public Relations (PR) firms to do it for them. In so doing, they show the slippage between business, government and social services. In looking for proposals from PR and marketing firms to run a campaign around sexualized drug use, the GMSH say they are looking for a "creative agency to support the development of a multifaceted, highly visible campaign for GBMSM [Gay Bisexual Men who have Sex with Men] across Ontario" where 
Our hope is that it will become a recognized "go to" site for GBMSM who are seeking information and support around sex and substance using behavior. Several communities (ranging from large urban centers such as Toronto and Ottawa to smaller northern communities such as Sudbury) will be participating.

The RFP is for an agency to guide the construction of a website and promote a campaign aimed at men who are at "higher-risk" of contracting HIV and other STBBI's as well as the other possible "harms" associated with substance use and "connecting them in real time to services." They want the services of an external agency to help "drive guys to the website" and connect them in real-time to services.

Arguably it is website usage (website analytics) that will be measured when reporting on the success of the project. What that means in practice, though, needs to be broken down into its constitutive data points to get a fuller picture of the kinds of data fragments that will be compiled. Because the website is online, and people can be connected to services in real-time across Ontario, the kinds of information on regional and provincial trends that people will give up just by using the website is significant. For example, do people who have IP's from Sudbury connect with services more often than those in Toronto? For anything in particular? Are they of similar age ranges?

The move to mining and analyzing data that freely traverses multiple sectors of the economy is already at hand. Google analytics is a marketing service provided by Google which works through tracking datapoints via website traffic to help customers understand their client base. A 2021 Google Analytics blog post featured a Pittsburgh food security charity that used Google Analytics to "... recruit volunteers" in order to become "food waste heroes" delivering 
food that would have ended up in dumpsters to people living with food insecurity. With talk of boosting engagement and tracking how people engage with the organization online, business strategies are being marketed to non-profit consumers by Google. The blog describes Google's machine learning approach to marketing analytics that are useful in helping consumers maximize client engagement:

With automated insights generated through machine learning, 412 Food Rescue has been able to save time analyzing data and spend more time taking action. They learned, for example, that there was a dip in volunteer engagement on weekends, an insight that had gone unnoticed. Because they had been proactively alerted to the change in Analytics, they were able to quickly respond by increasing their marketing efforts on weekends to boost engagement and address the demand for local deliveries on those days (Ackerman, 2021).

Google Analytics compiles multiple forms of data through web traffic and apps whereby users can customize up to fifty unique attributes to track. On a Google Analytics help page, I found a list of available attributes which one can track. For example, one's city location can be tracked, along with web browser, type of device used, how long one stays on a particular page, and which website one encountered one's ad (https://ga-dev-tools.web.app/dimensions-metricsexplorer/). A lot of information can be gleaned from such data fragments to track and predict future consumer/client actions. For my example, such databases already used by other charities potentially create rich insights into the habits of gay men who use drugs along with their broad socio-demographic information such as the devices they use, their location and how they interact with content. 
Through reporting, the government may be granted access to data doubles about queer men who use drugs who are 'difficult to reach' across the province of Ontario. How this data is used to make claims about queer men who use drugs connects to the ways in which the government can problematize them and open them up for further intervention based on the information they have been provided. Also significant is the way in which the primacy of data collection turns people into fragments - as I have already made clear in the literature review section and in my analysis sections - and reconstructs them via user-selected attributes and how those datasets traverse multiple sectors of the economy. It is unclear how the government will learn to make claims about queer men who use drugs as a result of this project, but I imagine this information is already being utilized in multiple sectors. It's not the services which are the problem, but how the government is framing funding to do certain things with groups of people who are 'hard to reach.' People, in this case queer guys who use drugs, are being made available to the government through a website put together by a marketing firm but run through an organization claiming to serve their needs. Does the website provide which types of data is being collected from them, for example? Does it make visible the multiple organizations working on the project?

The quantitative data generated through bits of information construct people in a way that Cheny-Lipold (2017) argues has no foundational epistemic meaning. Data produces doubles of people that are constantly changing and inherently fragmentary. It is an inherently incomplete picture of someone based on fragmentary pieces of data (such as age, location, action(s), supports requested etc.). Reporting to the GMSH can be understood as a means by which people become knowable via the traces that are captured about them and stored quantitatively in comparison to all the other users and potentially other data sets as well (i.e. how one group 
compares to the general population). Ultimately this data is provided to the government when it comes to reporting on the project. Upon such reporting, the government might come into contact with many constructs of people using the website who may not have been previously known to them before and contains potentially very intimate details of their lives including their HIV status and/or their use of criminalized substances. Even if the data is anonymous, it still provides the government with metadata that is useful when triangulated with other datasets.

I see very little room here for queer substance users to engage in the process of consenting to what information is being collected from them and I do not see much of an opportunity for queer substance users to narrate back from their experiences about what substance use means to them. The website will connect them to resources and professional supports, however, there is no mention of peer programming being part of a possible referral system. I believe this speaks to the way in which people are empowered to speak on behalf of others which further confines and constrains already vulnerablized people and communities.

It is also of interest that the GMSH is appealing to the expertise of outside agencies to fulfil the needs of the grant. Interesting as well that the GMSH, in the detailing of their rationale, make clear that they are changing their approach based on changes in their "strategic plan that emphasizes tailored campaigns and resources for different sub-communities of gay men (i.e.: gay men who use drugs)" coupled with "a new provincial HIV/AIDS strategy by the Ministry of Health and Long-term Care." It seems possible that they are changing their strategic plan to reflect new directions advanced by the Ministry. Engaging with private companies to do this kind of work means that data will potentially flow between private business, social service providers and government. This kind of data movement is taken up by van Dijk's (2014) exploration of the free-flow of data between state, business and academia. What this RFP adds 
to the discussion is that social service providers need to be included in such a matrix of power. The free-flow of data produces possibilities for the real-time surveillance of people based on their data which Dijk refers to as 'dataveillance.' There is coordination taking place with social service providers acting as the middle point between business and government attracting 'vulnerablized' or "hard to reach" or "niche" people to provide valuable forms of data.

To close this chapter, I want to emphasize the GMSH RFP that describes the kind of communications company they want to hire and note that the business should have "[A]n understanding of how our needs may differ from the traditional marketing approaches geared to attract consumers to purchase a product." This phrasing suggests just how business-oriented social service provision can be. For one thing, that the GMSH's practices may differ blurs a line between social service (understood as a form of service divorced from the needs of the market) and business. Ultimately the goal of marketing is to encourage spending and brand loyalty from consumers in relation to the goods they buy. Businesses use data to tailor approaches when marketing products, and this approach and discourse may need be different when digitally outreaching to queer guys who use drugs across the province and encouraging them to use a website. That gay and bisexual men who use drugs are or can be understood as only maybe different than a person buying shoes to the organization who supposedly serves their interests leaves me with pause. I guess it just makes good financial sense. A website of information on sex and substance use is shown to be a product to be consumed and tracked in the same way shoes are a product to be consumed.

As I have stated above, the blurring between social service agencies and strategies of engaging a customer base is already underway. The strategies used by companies to understand their customers is seemingly useful in the non-governmental sector to better understand the 
habits of their clients or potential clients. The way biopolitical governance constructs people as problems is arguably aided through these kinds of analytics which produce identities for people by breaking them down to granular types of user-but-not-client generated datapoints and reassembled into narratives which can be turned into claims about needs and behaviors. I wonder how this affects the kinds of research and frameworks for working with people that social workers draw from.

Parton (2006) makes the claim that social workers increasingly draw from psychological literatures as opposed to sociological literatures as they respond to a need to provide, collect and manage large swaths of data. I wonder to what extent psychological knowledge bases might be more amenable to quantitative data sets as opposed to qualitative datasets for example. More research needs to be done to establish this connection more concretely and in a way which falls outside the scope of this project.

\section{Discussion}

This section highlights a few questions which emerged from my analysis and offers some insights into how social workers are resisting the erosion of social service work through unionizing. I highlight a few ways that social workers and their clients have utilized unions to undermine neoliberal transformations of practice. The point of this discussion is to explore in brief detail the ways in which social workers use the content of their working lives, those parts which they did not choose as the force by which they then organize against it. The neoliberalization of health and social service provision consists of both a suite of policies aimed at privatization of service delivery as well as a broader transformation of social life aimed at undercutting ideas of communality (Baines, 2010). Multiple processes have converged to 
influence social work practice and my analysis potentially points to some of the phenomenon I have identified in the literature while raising significant questions.

For example, many of the introduction and background sections of RFPs I analyze frame people as problems through an emphasis on what they do, do not do or what they don't have but should. Similarly, in many of the RFPs I sample, data is utilized to make the case as to why certain constellations of actions or behaviors or beliefs are problems and thus worthy of intervention. It is the way in which data becomes evidence where that evidence is presented as wholly factual that is interesting to me because none of the RFPs in my study make reference to whether or not community members have asked for interventions of any kind.

The RFPs I survey structure the application process in such a way as to likely negate significant and wholistic opportunities for engaging clients and community members in a process of program design and evaluation. Data was asked for in the application process to prove a need for the project which means that social workers likely need to have datasets on-hand before applying for funding. This means that time has be dedicated to the casual and on-going collection of information about people. Applicants were asked in every RFP to provide the details of the project they are applying to run including an evaluation schedule outlining when data will be collected and what it will consist of. This was true even for the smallest grant in the survey which had a maximum amount of $\$ 5,000$. The need to show how a program will meet funding goals means that social workers will likely need to tailor their project descriptions to advance pre-determined goals and I am curious about how that affects relationship building with clients. I also wonder to what extent this changes how social workers structure program applications and what that means for clients and community members in terms of the data they will need to provide or have provided at different points in time. 
Another question I have is how evaluation schedules might be read as evidence for a changing practice, potentially reflecting what Parton (2008) refers to as informational practice or a datafied (Dijk, 2014) practice. For example, if funding goals specifically outline behavioral change as the project goal, which literatures might social workers draw from to craft a successful proposal including what datapoints reporting softwares ask for and which forms of data do they bring to the fore? I wonder if that might lead social workers to lean on psychology literatures as opposed to sociology because one is better suited to easy quantification. I also wonder to what extent RFPs define out opportunities for meaningful client and community engagement and how such an absence is reflected in how social workers conceptualize their clients and the cause of client problems. I have noted that many of the RFPs I scan in my essay turn complex social phenomenon (like youth crime) into individual problems through explaining the problems in particular ways, sometimes with accompanying asks in terms of how the problem should be solved (as is the case with the City of Toronto Resilience Framework). The individualization of structural phenomenon is one such component of the social aspects of neoliberalism and the production of responsible subjects (Brown and Baker, 2013).

My analysis has indicated many potential problems in social work practice which positions social work in a potentially grey space in relation to the social justice commitments we are supposed to be enacting (CASW, 2005). I will attempt to root my analysis in the particular forms of relationality that Ilcan (2017) identifies as a result of thinking neoliberalism as a 'mobile assemblage' which binds groups of people together as the state enacts regimes of privatization (p. 212). I will explore this by looking to examples of how social workers engage with unions to argue that social workers have used their unions to articulate problems in their workplaces as being intimately bound up with the lives of their clients and in some cases invited 
service users to engage in processes normally understood as being applicable to workers alone. I will conclude by looking at an example of how social workers were able to create children's programming in a unionized women's shelter in Toronto through collectively threatening management and facilitate the construction of a mental health program rooted in a class analysis. What I wish to highlight in this section is that social workers are, in perhaps small ways, using the content of their working lives as a means to engage in organizing for more convivial forms of social service delivery that re-collectivizes people and places.

Ilcan (2007) argues that neoliberalism should be understood as a "mobile assemblage" in the remaking of liberal social governance. She writes that as the state attempts to refract social norms and institutions through the image of market rationalities and personal responsibility, groups of people become bound together in novel ways, most notably as problems. One example would be of single mothers and pensioners who became symbols of dependence on the state for their livelihoods. Ilcan refers to this process as a mobile assemblage in two ways. The first being the way that whole groups of people become problems in ways which bind them together but who might have had no previous relation to each other. Second is that because she argues for neoliberalism as being unstable, contextual and non-linear, people will be bound up together differently and through different labels because projects of privatization are locatable to places and spaces.

As the state begins to formulate groups of people as problems, new forms of relationality are also produced between people whose lives lie in tension with the state (Ilcan, 2007, p. 212). I would like to add that such a process also likely brings new groups of people into contact with social workers and so social workers are also similarly brought into relation with those groups as well. 
Ilcan (2007) further states that beginning in the 1980s and 1990s government service providers began to be articulated as inefficient partly due to the unions representing them and thus, infringed on the market determining among other things, what people ought to be paid for their labour and what 'consumers' (or the public) of services actually wanted. She writes of public service reform in the 1980s and 1990s: “...the Canadian federal government during the 1980s and early 1990s engaged in privatizing crown corporations, contracting-out public service work, and reducing the availability and accessibility of a wide range of public services" (p. 215). Some of the reforms also included new management styles including flexibilizing labour and making individual employees responsible for greater volumes of tasks.

Beginning in the late 1990s the Federal government introduced 'benchmarking' or standardization practices into former public services being contracted out to NGOs. This was done to ensure 'accountability' to public funds and to meet increasingly narrow performance targets (p. 217-218). This means that reforms leading to the privatization of service provision also depended on the use of NGOs where the government introduced performance metrics as a means to ensure greater oversight over the affairs of agency staff and time. Additionally, this means that the working lives of social workers changed and thus introduced to new groups of people as the state began contracting out services they once provided. Ilcan writes of the effects of mobile assemblages that: "[m]any groups today are learning firsthand how certain neoliberal policy orientations and programs encourage a rethinking of responsibility, and of who is identified as crucial in resolving social, economic, or political problems" (p. 212). My thought here is of relationality and what that means for social workers who are caught up in systems that constrain what we do and how in similar enough ways to our clients. 
Donna Baines (2010) outlines some of the effects neoliberal policy regimes have had on social service agencies. She writes that one of the effects was to imbue social service provision in individualist terms turning service users into consumers and isolating social service workers from their clients and from other social workers. As project funding replaces core funding, agencies need to compete with each other to keep services running which sometimes means undercutting the competition leading to lower wages. At the same time, agencies need to turn to new sources of funding in order to fill gaps which has increased the time spent collecting data, filing paper work and reporting on small pots of funding. The time spent applying for funding could have been used doing other things including spending time with clients (pp. 12-13). As funding gets tighter, and as staff numbers gradually thin out, so too have opportunities for social workers to work together as colleagues. Social work, to Baines (2004), has become increasingly lonely. One social service worker Baines interviewed noted that her organization stopped sending workers to conferences and that department-wide meetings had effectively stopped at her agency in Alberta (p. 280).

One of the surprising notes in Baines' (2010) paper was that as the working lives of social workers changed under an ideology of privatization, social service workers unionized in greater numbers than on average. At the time of publication, approximately 38.7 percent of workers in community services were represented by a union compared to 29 percent of workers in total (pp. 17-18). Some of the motivations shared by research participants as to why they were involved with their union indicated that unions provided opportunities to reconceptualize the goals of their professional lives. For example, some of the interviewees noted that all the time spent doing paperwork and documentation kept them from doing other tasks more aligned with their vision of social work practice including community mobilization and organizing. 
Additionally, when social workers spoke about why they were invested in their union, they framed their particular problems in the workplace within a broader structural context which included their clients and communities. They, in other words, made no clear distinction between their material conditions and the material conditions of the people they serve (p. 19).

What I take this to mean is that the community infrastructures can actually change the knowledge bases social workers adopt to understand and address problems. The reasons social workers gave for participating in their unions were varied in the study but one of the justifications reflected a desire to change their working conditions and change how they related to their communities and colleagues. In other words, the desire for engagement in their unions emerged as a result of neoliberal restructuring and not necessarily as an idealistic imagining of a better society disconnected from history.

In a discussion about countering the deprofessionalization of social work, Healy and Meagher (2011) advance what they call social unionism as one such avenue. They define deprofessionalization as the ways in which professional social work is devalued through a combination of: funding models incentivizing low wages, project funding negating consistent employment, and the hiring of workers without social work or social service work degrees (pp. 244-249). There are two interesting aspects to the social unionism model they explore through case studies from Norway, Sweden and the UK. The first is that social workers are likely to leverage their union to secure wins in their contract which advance issues important to their clients as well as themselves. The second is a cooperative model of partnership by which social workers make adjustments to how membership is understood in order to broaden it. In one of the examples from Sweden's social service worker union, Kommunal, strong alliances are maintained between members and non-members including social service users who are invited in 
some decision-making processes. As a result, one of the core tenets of Komunal includes "everyone who requires welfare will receive it" (253-254) broadening traditional notions of membership being tied to their status as employees, how individual workplaces can be understood in a broader context and what social justice looks like. Welfare for all is a universalist notion in that the tenet was not "welfare for all Swedes who need it."

Ben Carniol (2000) cites two practical examples of how social workers have utilized their unions to better working conditions for clients. The first is from an interview with a social worker who was employed by an emergency women's shelter in Toronto. She told Carniol:

[b]esides the problems associated with the overcrowding issue, we had been pushing for a children's program in the shelter. The union called a meeting with the shelter's management and at that meeting the union demanded action. Soon after, the children's program was established and other conditions improved as well (pp. 139-140).

Carniol (1990) writes that social workers in unions have been able to advance new models of counselling as well. At the time of Carniol's writing, unions were sponsoring their own counselling programs and hiring social workers. Some of the programs began to formulate counselling around the idea that waged work is a primary source of people's personal problems (pages 123-124). Given that it is union members providing counselling to other union members, this model of by and for counselling frustrates a largely unhelpful binary which often sits at the centre of social work education: that of the client and service provider as being neat and separate categories (along with its classed, raced and gendered connotations).

To close, social workers are using the material conditions of their workplaces as a means to organize and provide a re-articulation of what social services should be and who they should 
include. For example, social workers have used their unions to bargain for contracts which make their working lives better, such as in reduced caseloads, but that also translates into resisting datafication in the process as reporting softwares also facilitate higher caseloads. Less reporting and casework may also potentially translate into more time spent working in community. More time with community might involve the thinking of social work in less linear terms and more relationally.

There are many types of union structures and so there is no silver bullet for addressing social work's increasing precarity, reliance on performance metrics along with its relationship to social control. It is affirming, though, that social workers are using their unions to bargain for themselves and their communities as inhabiting a shared world. For example, the creation of children's programming in an emergency shelter. Social workers are also invested in unions as a means to re-socialize their workplaces as evidenced in the discussion of social workers wanting to unionize so they could spend more time in community or include ideas which make no distinction between citizens and non-citizens in the case of Kommunal in Sweden.

\section{Conclusion}

My research has provided insights into various topics highlighted in the literature. Linear time is shown to be a structuring variable facilitating a datafied or informational social work practice. Short-term RFPs are also shown to be productive objects of inquiry for locating trends shaping contemporary practice. The context and/or background sections of the short-term RFPs I analyzed positioned people as problems in 3 broad ways: 1) RFPs construct people as problems based on what they do or are likely to do; 2) RFPs construct people as problems based on what they do not have enough of, and 3) RFPs construct people as problems based on what they do not 
do but should. This connects to biopower in that the government is implicated in the construction of people as problems requiring attention and alteration.

Similarly, short-term RFPs deconstruct community members into particular empirical inputs to be measured over time. RFPs highlight problems they want social workers to address through particular frameworks being tracked via specific inputs and outputs. What it tells me is that the datafication of practice, or the turn towards informational social work (Parton, 2006) is well underway in contemporary social work practice in Canada. The fact that these projects are short-term negates holistic forms of project design and reporting and promotes organizations accepting government narratives about both the causes and solutions of social problems. Linear time structures such a transformation in two ways: 1) it facilitates the easy capture and analysis of data and 2) facilitates relatively prescribed forms of working with people that align with the constraints of short-term funding. The ways in which RFPs reduce people to data points also depoliticizes social problems as individual problems.

The ways in which short-term RFPs ask organizations to apply further shows the datafied nature of contemporary practice. The ways in which organizations were tasked to show "need" and other related categories were all quantitative in nature and imply comparison. This furthers the idea that quantifiable information is objective in character and supplants other forms of justifications and knowledge production. Quantifiable data comes to act as a stand-in for decision making processes.

The way in which data factors into decision making processes is also shown to be important in that it might help explain processes relating to how activities are delisted for future funding. Importantly, though, it also implicates social workers reporting on social workers in 
similar ways that they do with clients. In so doing, it potentially implicates the responsibilisation of professional social service workers.

Finally, my research has indicated that in at least one RFP, a clear blurring of boundaries between social service providers, government and business is already present. Additionally, my research indicates the neoliberalization of practice is taking place concurrently with the datafication of practice in the privileging of business logics via an RFP seeking marketing and PR agencies in the running of a publicly funded social service. The specificity of data collected in the reporting process is immense when datasets flow between government, social service provider and business.

Research has also indicated that social workers are finding the effects of neoliberal social service work alienating and not-in service of their clients. There are efforts undertaken by social workers in a number of countries to counteract the detritus effects of neoliberal practice (austerity, thinning of staff numbers, isolated social workers etc.) through unionizing in greater numbers, expanding the scope of union participation by including clients and confronting management in creating programs and services that are of benefit to their clients.

\section{Future Directions}

Although my research has pointed to a number of trends indicated in the literature, the sample size (8 RFPs) is low, meaning generalizability is made difficult. A number of areas could be expanded upon. One area of additional research concerns the material effects of informational social work. It would be useful to interview clients of services to see how they experienced data collection and how processes of data collection were communicated to them by social workers. It would also be useful for researchers to conduct interviews with practicing 
social workers to see how they use data when applying for grants, report on projects along with the data they collect from clients. Finally, it would be interesting to research social work pedagogy to see which knowledge bases social work students are being taught from to see if psychological literatures are being drawn from more often than sociological ones. 


\section{Works Cited:}

Arvidson, M., \& Lyon, F. (2013). Social impact measurement and non-profit organisations: compliance, resistance, and promotion. VOLUNTAS: International Journal Of Voluntary And Nonprofit Organizations, 25(4), 869-886.

Baines, D. (2004). Caring for nothing: Work, organization and unwaged labour in social services. Work, Employment And Society, 18(2), 267-295. https://doi.org/10.1177/09500172004042770

Baines, D. (2016). Moral projects and compromise resistance: Resisting uncaring in nonprofit care work. Studies In Political Economy, 97(2), 124-142.

\section{https://doi.org/10.1080/07078552.2016.1208793}

Baker, S. and Brown, B. (2013). Responsible citizens: Individuals, health and policy under neoliberalism. 1st ed. New York City: Anthem Press, pp.9-46.

Beresford, P. (2005). Redistributing profit and loss: the new economics of the market and social welfare. Critical Social Policy, 25(4).

Bloch, S. (2020). Broken windows ideology and the (mis)reading of graffiti. Critical Criminology (Richmond, B.C.), 28(4), 703-720. https://doi.org/10.1007/s10612-01909444-w

Blouin, G. (2020). Data performativity and health: The politics of health data practices in Europe. Science, Technology, \& Human Values, 45(2), 317-341.

\section{https://doi.org/10.1177/0162243919882083}

Browning, B. A. (2014). Grant writing for dummies (5th ed.). Wiley Pubishing, Inc. 
Bryant, T., Raphel, D., Schrecker, T., \& Labonte, R. (2011). Canada: A land of missed opportunity for addressing the social determinants of health. Health Policy, 101(1). https://doi.org/10.1016/j.healthpol.2010.08.022

Carniol, B. (1999). Social work and the labour movement. In B. Wharf (Ed.), Social work and social change in Canada (pp. 114-144). Oxford University Press Canada.

Carniol, B. (2000). Social work and social change: Towards a liberation practice. In Case critical: Challenging social services in Canada (4th ed., pp. 114-149). Between The Lines.

CASW Code of Ethics. Canadian Association of Social Workers. (2005). https://caswacts.ca/en/Code-of-Ethics.

Cheney-Lippold, J. (2017). Categorization: Making data useful. In We are data: Algorithms and the making of our digital selves (pp. 37-93). New York University Press.

Cheney-Lippold, J. (2017). Control: Algorithm is gonna get you. In We are data: Algorithms and the making of our digital selves (pp. 93-151). essay, New York University Press.

Chow, D., Greatbatch, D., \& Bracci, E. (2019). Financial responsibilisation and the role of accounting in social work: Challenges and possibilities. The British Journal Of Social Work.

Clague, M. (1997). Thirty turbulent years: Community development and the organization of health and social services in British Columbia (B. Wharf \& M. Clague, Eds.). In Community organizing: Canadian experiences. (pp. 91-112). Toronto: Oxford University Press.

Clement, D. (2019). How the state shaped the nonprofit sector: Public funding in British Columbia. Canadian Review of Sociology, 56(3), 299+. 
Cruikshank, B. (1999). The will to empower: Democratic citizens and other subjects. Cornell University Press.

Dunlop, J. (2019). Privatization: How government promotes market-based solutions to social problems. Critical Social Work, 7(2).

Foucault, M. (1990 a). Right of Death and Power over Life . In The history of Sexuality . essay, Vintage Books.

Foucault, M. (1990 b). The history of sexuality. Vintage Books.

Foucault, M. (2002). The archeology of knowledge. Routledge .

Garrett, M., P. (2016). Questioning tales of "ordinary magic": "Resilience" and neo-liberal reasoning. The British Journal of Social Work, 46(7), 1909-1925. https://doi.org/10.1093/bjsw/bcv017

Garrity, Z. (2010). Discourse analysis, Foucault and social work research. Journal Of Social Work, $10(2)$.

Gibson, K., O'Donnell, S., \& Rideout, V. (2007). The project-funding regime: Complications for community organizations and their staff. Canadian Public Administration/Administration Publique Du Canada, 50(3), 411-436. https://doi.org/10.1111/j.17547121.2007.tb02135.x

Hall, C., Parton, N., Peckover, S., \& White, S. (2010). Child-centric information and communication technology (ICT) and the fragmentation of child welfare practice in England. Journal Of Social Policy, 39(3),

Healy, K., \& Meagher, G. (2004). The reprofessionalization of social work: Collaborative approaches for achieving professional recognition. British Journal Of Social Work, 34(2), 243-260. https://doi.org/10.1093/bjsw/bch024 
Herd, D. (2002). Rhetoric and retrenchment: 'Common sense' welfare reform in Ontario. The Journal of Poverty and Social Justice, 10(2), 105-110.

Ilcan, S. (2009). Privatizing responsibility: Public sector reform under neoliberal government. Canadian Review Of Sociology/Revue Canadienne De Sociologie, 46(3), 207-234. https://doi.org/10.1111/j.1755-618x.2009.01212.x

Jäger, S. (2001). Discourse and knowledge: Theoretical and methodological aspects of a critical discourse and dispositive analysis. In R. Wodak \& M. Meyer (Eds.), Methods of Critical Discourse Analysis (Vol. 1, pp. 32-59). essay, SAGE.

Juhila, K., \& Abrams, L. (2011). Special issue editorial: Constructing identities in social work settings. Qualitative Social Work, $10(3$

Kamalu, N., \& Onyeozili, E. (2018). A critical analysis of the "broken windows" policing in New York City and its impact: Implications for the criminal justice system and the African American community. African Journal of Criminology and Justice Studies, 11(1), 71-94.

Kennedy, H., Poell, T., \& Dijck, J. van. (2015). Data and agency. Big Data and Society, 1(5), 17. https://doi.org/10.1177/2053951715621569

Kenny, S. (2016). Changing community development roles: The challenges of a globalising world (R. Meade, M. Shaw, \& S. Banks, Eds.). In Politics, Power and Community Development (Rethinking Community Development, pp. 47-65). Bristol: University of Bristol.

Knight, M., \& Rodgers, K. (2012). “The government is operationalizing neo-liberalism”:

Women's organizations, Status of Women Canada, and the struggle for progressive social 
change in Canada. NORA - Nordic Journal of Feminist and Gender Research, 20(4), 266-282. https://doi.org/10.1080/08038740.2012.747786

Lockett, D. (2020). Grants 101: A how-to guide for nonprofits [web log]. https://www.imaginecanada.ca/en/360/grants-101-how-guide-nonprofits).

Mayer-Schönberger, V., \& Cukier, K. (2013). Big data: A revolution that will transform how we live, work, and think. Houghton Mifflin Harcourt.

Million, D. (2013). Therapeutic nations: Healing in an age of Indigenous human rights. The University of Arizona Press.

Munro, E., \& Hardie, J. (2018). Why we should stop talking about objectivity and subjectivity in social work. The British Journal Of Social Work, 49(2), 411-427.

Noonan, K., Sabel, C., \& Simon, W. (2009). Legal accountability in the service-based welfare state: Lessons from child welfare reform. Law \& Social Inquiry, 34(03).

Park, Y. (2008). Making refugees: A historical siscourse analysis of the construction of the 'refugee' in US social work, 1900-1957. British Journal Of Social Work, 38(4), 771787.

Parton, N. (2006). Changes in the form of knowledge in social work: From the 'social' to the 'informational'?. British Journal Of Social Work, 38(2), 253-269

Roberts-Holmes, G., \& Bradbury, A. (2016). Governance, accountability and the datafication of early years education in England. British Educational Research Journal, 42(4), 600-613.

Rolnik, R. (2013). Late neoliberalism: The financialization of homeownership and housing rights of the poor. International Journal of Urban and Regional Research, 37(3), 1058-1066. https://doi.org/10.1111/1468-2427.12062 
Ruckenstein, M. and Schüll, N., 2017. The datafication of health. Annual review of anthropology, 46(1), pp.261-278.

Silver, J. (2016). Solving Poverty: Innovative Strategies from Winnipeg's Inner City. Halifax NS: Fernwood Publishing.

Trinder, L. (2000). Introduction: the context of evidence-based practice. In L. Trinder \& S. Reynolds (Eds.), Evidence-Based Practice: A critical Appraisal (pp. 1-17). Hoboken, NJ: Wiley-Blackwell.

van Dijk, T. A.(2008). Structures of discourse and structures of power . In Discourse and power (pp. 27-65). Palgrave Macmillan.

van Dijck, J. V. (2014). Datafication, dataism and dataveillance: Big data between scientific paradigm and ideology. Surveillance \& Society, 12(2), 197-208. https://doi.org/10.24908/ss.v12i2.4776

Wodak, R., \& Meyer, M. (2001). Methods of critical discourse analysis. SAGE.

\section{Appendix A}

How data was collected and recorded

This appendix provides a reference as to how data was collected and recorded. 

RFP: Toronto Urban Health Fund (TUHF) - Child and youth resiliency stream + Toronto Urban Health Child and Youth Resiliency Funding
Guide

Date: 2017-2020

How does the RFP describe the population or behavior?

\begin{tabular}{|c|c|}
\hline $\begin{array}{l}\text { Is a population or populations described via problems or problematic behavior(s) that } \\
\text { require agency attention? }\end{array}$ & Yes. \\
\hline If yes, describe. & $\begin{array}{l}\text { The populations requiring intervention engage in risky behavior which reduce their } \\
\text { resiliency or capacity to "bounce-back" from problems leading to problematic health and } \\
\text { social outcomes. }\end{array}$ \\
\hline Is the problem or problems split into multiple or overlapping syndemic factors? & $\begin{array}{l}\text { Yes. Lack of resiliency in childhood and youth leads to problems later in life including } \\
\text { physical and mental health, violence and other aggressive behaviors, adjustment problems } \\
\text { in family, school and workplaces, unplanned pregnancies, STI transmission, emotional } \\
\text { and social trauma, substance use and injuries and death related to school/other drug use. }\end{array}$ \\
\hline $\begin{array}{l}\text { Is the problem or problems presented in the RFP supported by data or references to } \\
\text { data? }\end{array}$ & Yes. Nine sources listed. \\
\hline $\begin{array}{l}\text { Does the RFP make reference to previous projects in describing an approach they want } \\
\text { organizations to take when working with a population or addressing a behavior? }\end{array}$ & Yes. \\
\hline \multirow[t]{2}{*}{ If yes describe. } & $\begin{array}{l}\text { They want evidence based interventions reducing risk and building developmental assets. } \\
\text { They city four proven forms of intervention } \\
\text { 1) Social Resistance Training - increasing awareness of social influences and } \\
\text { building skills to respond to them. } \\
\text { 2) Normative Education - Providing accurate "picture" of sexual and substance use } \\
\text { prevalence for their age group to dispel the notion that it's a normal thing for their } \\
\text { peers to be doing. }\end{array}$ \\
\hline & $\begin{array}{l}\text { 3) Competence Enhancement Skills Training - Teaching a combination of life and } \\
\text { social skills including problem solving, self-control, self-esteem, anxiety and } \\
\text { stress relief and social and assertive skills. } \\
\text { 4) Family-Based Interventions - Bonding and communication skills, helping } \\
\text { children develop pro-social and social resistance skills, rule-setting techniques } \\
\text { and reducing aggressive and/or anti-social behavior. }\end{array}$ \\
\hline $\begin{array}{l}\text { Is the population, populations or problem or problems referenced requiring attention } \\
\text { justified in relation to government or agency priority (strategic plans for example). }\end{array}$ & YES. \\
\hline If yes, describe. & $\begin{array}{l}\text { Ontario Public Health Standards objectives of: } \\
\text { 1) To increase access to sexual health and harm reduction services that prevent } \\
\text { exposure to and the transmission of HIV } \\
\text { 2) To increase the practice of healthy behaviors among populations with respect to } \\
\text { sexual practices and injection drug use as they relate to preventing and reducing } \\
\text { exposure to HIV } \\
\text { 3) To increase the practice of healthy living behaviors and personal skills for } \\
\text { preventing substance use and reducing harms associated with substance use }\end{array}$ \\
\hline $\begin{array}{l}\text { Does the RFP contain a description of whether or not the particular communities have } \\
\text { asked for an intervention or been consulted? }\end{array}$ & No. \\
\hline \multicolumn{2}{|l|}{ If yes, describe. } \\
\hline $\begin{array}{l}\text { How many times do the words "risk," "risk reduction," "risky behavior," "at-risk," } \\
\text { "high-risk," "crisks," "risky," "risk-taking," "disadvantaged," "disadvantage," } \\
\text { vulnerable" and "marginalized" appear in the RFP? }\end{array}$ & $\begin{array}{l}\text { Risk }-8 \\
\text { High-Risk }-6 \\
\text { Risks }-1 \\
\text { Risky }-2 \\
\text { At-Risk }-1 \\
\text { Risk-taking }-1 \\
\text { Vulnerable }-1 \\
\text { Marginalized }-2 \\
\end{array}$ \\
\hline
\end{tabular}


The proposed project

\begin{tabular}{|c|c|}
\hline Does the RFP ask for a project timeline to be submitted in the application? & Yes. \\
\hline Does it further specify to include milestones or particular markers of success? & Yes \\
\hline If so, describe. & $\begin{array}{l}\text { It asks for a Behavior Intervention Plan indicating that each stage of the intervention will } \\
\text { take place and how it will be measured. } \\
\text { In addition, it asks you to identify target population, rational for project, What you will be } \\
\text { doing with the population and goals and objectives and how they will be measured. You } \\
\text { also need to show the evidence supporting what you will do with who and how the } \\
\text { outcomes of the project can be measured. }\end{array}$ \\
\hline $\begin{array}{l}\text { Does the RFP ask agencies to apply with examples of prior work experience in a } \\
\text { related project, working with a particular population or demonstrate certain } \\
\text { knowledges? }\end{array}$ & No. \\
\hline \multicolumn{2}{|l|}{ If yes, describe. } \\
\hline \multicolumn{2}{|l|}{ Reporting obligations } \\
\hline Does the RFP outline certain deliverables? & The funding is meant to advance several priorities. \\
\hline If yes, describe. & $\begin{array}{l}\text { Priorities are: } \\
\text { 1) To increase personal agency among children and youth by working with them to } \\
\text { identify and reduce their individuals strengths and assets in ways that help them } \\
\text { avoid or reface vulnerability }\end{array}$ \\
\hline & $\begin{array}{l}\text { 2) To increase resourcefulness by equipping children and youth with the skills to } \\
\text { successfully navigate situations should they engage in behaviors that put them at } \\
\text { risk of HIV transmission and/or substance use } \\
\text { 3) To promote social and emotional competence for children and youth faced with } \\
\text { adversity, and enabling them to transform stressful situations into opportunities to } \\
\text { learn and thrive } \\
\text { 4) To enhance child and youth engagement with resourceful environment, } \\
\text { communities, and life settings that promote health } \\
\text { 5) To increase the capacity of organizations and the community to promote health } \\
\text { and offer services within resiliency framework }\end{array}$ \\
\hline Will the deliverables need to be supported through data? & Unclear in a literal reading. \\
\hline If it's not obvious, can you infer? & Yes. \\
\hline If so, describe them. & $\begin{array}{l}\text { It is overwhelmingly behavioral in nature, especially considering that organizations need } \\
\text { to submit a Behavioral Intervention Plan and the language utilized is around risk and } \\
\text { avoiding risky behaviors. }\end{array}$ \\
\hline
\end{tabular}


RFP: New Horizons Grant for Senior's Program (Employment and Social Development Canada) + Applicant Guide

Date: 2017-2020

How does the RFP describe the population or behavior?

\begin{tabular}{|c|c|}
\hline $\begin{array}{l}\text { Is a population or populations described via problems or problematic behavior(s) that } \\
\text { require agency attention? }\end{array}$ & $\begin{array}{l}\text { Not literally, however the fund only funds activities which address vulnerabilities such as } \\
\text { addressing mental health or combatting ageism which suggests that qualities are being } \\
\text { highlighted. }\end{array}$ \\
\hline \multicolumn{2}{|l|}{ If yes, describe. } \\
\hline Is the problem or problems split into multiple or overlapping syndemic factors? & No. \\
\hline $\begin{array}{l}\text { Is the problem or problems presented in the RFP supported by data or references to } \\
\text { data? }\end{array}$ & No. \\
\hline $\begin{array}{l}\text { Does the RFP make reference to previous projects in describing an approach they want } \\
\text { organizations to take when working with a population or addressing a behavior? }\end{array}$ & No. \\
\hline \multicolumn{2}{|l|}{ If yes describe. } \\
\hline $\begin{array}{l}\text { Is the population, populations or problem or problems referenced requiring attention } \\
\text { justified in relation to government or agency priority (strategic plans for example). }\end{array}$ & $\begin{array}{l}\text { Yes. The government of Canada has highlighted particular vulnerabilities they want } \\
\text { addressed. }\end{array}$ \\
\hline \multirow[t]{2}{*}{ If yes, describe. } & $\begin{array}{l}\text { Program objectives: } \\
\text { Promoting Volunteerism among seniors } \\
\text { Engaging seniors in the community through the mentoring of others } \\
\text { Expanding awareness of elder abuse, including financial abuse } \\
\text { Supporting the social participation and inclusion of seniors } \\
\text { Providing capital assistance for new and existing community projects and programs for } \\
\text { seniors }\end{array}$ \\
\hline & $\begin{array}{l}\text { National Priorities (these are priorities for seniors set by SEDC): } \\
\text { Supporting healthy aging: } \\
\text {-addressing social isolation } \\
\text {-mental health and dementia } \\
\text {-supporting accessible intergenerational housing } \\
\text { Preventing Elder Abuse: } \\
\text {-measures to reduce crimes and harm against seniors } \\
\text {-supporting financial empowerment of seniors } \\
\text { Combatting Ageism and celebrating Diversity Promoting Social Inclusion: } \\
\text {-Promoting labour market participation } \\
\text { - Particularly members of underrepresented and underserved group including } \\
\text { a) women } \\
\text { b) INdengeus peoples } \\
\text { c) Persons with Disabilities } \\
\text { d) members of racialized and newcomer groups } \\
\text { e) members of LGBTQ+ communities } \\
\text {-Promoting intergenerational mentoring and engagement } \\
\text { Improving Seniors' Access to Government Services and Benefits } \\
\text {-helping seniors navigate access to government benefits } \\
\text {-providing support to file their taxes } \\
\text { Adapting Community-Based Organizations to a more Virtual Environemnt } \\
\text {-by developing and delivering programming } \\
\text {-recruiting and training volunteers to support the social inclusion of seniors }\end{array}$ \\
\hline $\begin{array}{l}\text { Does the RFP contain a description of whether or not the particular communities have } \\
\text { asked for an intervention or been consulted? }\end{array}$ & No. \\
\hline \multicolumn{2}{|l|}{ If yes, describe. } \\
\hline $\begin{array}{l}\text { How many times do the words "risk," "risk reduction," "risky behavior," "at-risk," } \\
\text { "high-risk," "risks," "risky," "risk-taking," "disadvantaged," "disadvantage," } \\
\text { vulnerable" and "marginalized" appear in the RFP? }\end{array}$ & Marginalized - 2 \\
\hline
\end{tabular}


The proposed project

\begin{tabular}{|c|c|}
\hline Does the RFP ask for a project timeline to be submitted in the application? & Yes. \\
\hline Does it further specify to include milestones or particular markers of success? & Yes. \\
\hline If so, describe. & $\begin{array}{l}\text { You need to demonstrate how your project meets at least one of the project objectives } \\
\text { listed above. } \\
\text { You need to demonstrate how need was determined for the project } \\
\text { You need to demonstrate how your project will address the need and meet at least one } \\
\text { program objective } \\
\text { Hoe your project will reflect proper guidance related to health in relationship to COVID. } \\
\text { How you identify the cost associated with your project } \\
\text { You need to identify in your proposal who will do what is listed and when. } \\
\text { Indicate the target population } \\
\text { Demonstrate how seniors were involved in developing and will be involved in running the } \\
\text { project } \\
\text { Identify which linguistic groups are being prioritized. }\end{array}$ \\
\hline $\begin{array}{l}\text { Does the RFP ask agencies to apply with examples of prior work experience in a } \\
\text { related project, working with a particular population or demonstrate certain } \\
\text { knowledges? }\end{array}$ & $\begin{array}{l}\text {-explain how your organizations serves seniors (if applicable) } \\
\text {-Ensure to include if your organization offers accessible communication/information } \\
\text { technology in your community } \\
\text { Support letters for the project are mandatory } \\
\text { Letters must endorse the project and clearly demonstrate the following: } \\
\text {-your knowledge and support of the organization } \\
\text {-your knowledge and support of the proposed project } \\
\text {-the need that will be addressed by the proposed project in your community }\end{array}$ \\
\hline & \\
\hline
\end{tabular}

Reporting obligations

\begin{tabular}{|c|c|}
\hline Does the RFP outline certain deliverables? & Yes. \\
\hline If yes, describe. & $\begin{array}{l}\text { Project must satisfy the objectives identified in the application. } \\
\text { You must demonstrate seniors active engagement } \\
\text { You must demonstrate the number of seniors who benefited from the project. } \\
\text { Demonstrate how your project will improve social isolation of seniors } \\
\text { Demonstrate how seniors will benefit from the project } \\
\text { Demonstrate how it will benefit the wider community of seniors }\end{array}$ \\
\hline Will the deliverables need to be supported through data? & Unsaid. \\
\hline If it's not obvious, can you infer? & Likely. \\
\hline If so, describe them. & $\begin{array}{l}\text { There will likely need to be a mix of reporting done based on the objectives your are } \\
\text { attempting to receive funding for. } \\
\text { If for example, you are working on addressing isolation or mental health than the } \\
\text { reporting will be a mix of numbers attending programs or accessing services along with } \\
\text { behavioral data. }\end{array}$ \\
\hline
\end{tabular}


RFP:PHAC HIV and Hepatitis C Community Action Fund - 3 year duration + CAF Frequently Asked Questions document.

Date: 2021

How does the RFP describe the population or behavior?

\begin{tabular}{|c|c|}
\hline $\begin{array}{l}\text { Is a population or populations described via problems or problematic behavior(s) that } \\
\text { require agency attention? }\end{array}$ & Unclear \\
\hline If yes, describe. & $\begin{array}{l}\text { Particular people (women for example) and people who do particular things (people who } \\
\text { use drugs), are highlighted in relation to their risk of contracting and/or passing } \\
\text { HIV/Hepatitis C to others. }\end{array}$ \\
\hline Is the problem or problems split into multiple or overlapping syndemic factors? & $\begin{array}{l}\text { Not exactly but it does make a list of people who are to be targeted: } \\
\text { 1) Gay, Bisexual men and other men who have sex with men } \\
\text { 2) People who use drugs } \\
\text { 3) First Nations, Inuit, and Metis People } \\
\text { 4) Racialized people and migrants, particularly from regions with high HIV or } \\
\text { hepatitis C prevalence } \\
\text { 5) Sex workers and their clients } \\
\text { 6) People living in or recently release from correctional facilities } \\
\text { 7) Transgender and non-binary people } \\
\text { 8) People living with HIV or Hepatitis C } \\
\text { 9) Women among these populations as appropriate } \\
\text { 10) Youth among these populations, as appropriate }\end{array}$ \\
\hline $\begin{array}{l}\text { Is the problem or problems presented in the RFP supported by data or references to } \\
\text { data? }\end{array}$ & $\begin{array}{l}\text { Likely, considering that these populations are selected for their rates of, or risk of } \\
\text { contracting HIV and/or Hepatitis C }\end{array}$ \\
\hline $\begin{array}{l}\text { Does the RFP make reference to previous projects in describing an approach they want } \\
\text { organizations to take when working with a population or addressing a behavior? }\end{array}$ & Not exactly \\
\hline If yes describe. & $\begin{array}{l}\text { It needs to be evidence-based and so rooted in particular approaches. It's not to trial } \\
\text { particular kind of interventions. }\end{array}$ \\
\hline
\end{tabular}

\begin{tabular}{|c|c|}
\hline $\begin{array}{l}\text { Is the population, populations or problem or problems referenced requiring attention } \\
\text { justified in relation to government or agency priority (strategic plans for example). }\end{array}$ & \\
\hline If yes, describe. & \\
\hline $\begin{array}{l}\text { Does the RFP contain a description of whether or not the particular communities have } \\
\text { asked for an intervention or been consulted? }\end{array}$ & Unclear. \\
\hline If yes, describe. & $\begin{array}{l}\text { It doesn't make reference to whether particular communities wanted interventions of this } \\
\text { kind. } \\
\text { But it does make reference to engagement sessions with target populations to provide } \\
\text { input onto how projects should be funded. } \\
\text { It also mentions the idea of a "knowledge-broker," run by another organization, which } \\
\text { works to synthesize across the country with researchers and "end-users" which are } \\
\text { labelled as community organizations but not users of the service themselves. }\end{array}$ \\
\hline $\begin{array}{l}\text { How many times do the words "risk," "risk reduction," "risky behavior," "at-risk," } \\
\text { "high-risk," "risks," "risky," "risk-taking," "disadvantaged," "disadvantage," } \\
\text { vulnerable" and "marginalized" appear in the RFP? }\end{array}$ & 0 \\
\hline
\end{tabular}

The proposed project

\begin{tabular}{|l|l|}
\hline Does the RFP ask for a project timeline to be submitted in the application? & Yes. \\
\hline Does it further specify to include milestones or particular markers of success? & Yes. \\
\hline If so, describe. & $\begin{array}{c}\text { It asks to determine how need was determined where need can be shown through } \\
-\quad \text { The rate of infections in the geographic area } \\
-\quad \text { Relevant factors of transmission } \\
-\quad \text { Specific trends or challenges you seek to address } \\
-\quad \text { Evidence of effectiveness of the proposed approach }\end{array}$ \\
\hline
\end{tabular}


Evidence of effective interventions can be shown through

- Population-based surveys

- Jurisdiction-specific sources of data (reports focussed on specific key populations or with data disaggregated by populations)

- Research findings

- Project evaluations

You need to show how you will evaluate the effectiveness of your proposed project highlights

You also need to apply with an evaluation plan outlining how evaluation will take place, when it will take place, who it will take place with and what kind of data you will be collecting. It is looking for both Performance markers and Evaluation targets set out in the application.

Does the RFP ask agencies to apply with examples of prior work experience in a related project, working with a particular population or demonstrate certain knowledges? If yes, describe.

\section{Yes}

1) A minimum of two years of experience in the prevention and control of HIV, hepatitis C, and other STI or sexual health promotion; and

2) A minimum two years of experience working with (actively and meaningfully engaging) the proposed project's key population(s) as applicable.

Reporting obligations

\begin{tabular}{|l|l}
\hline Does the RFP outline certain deliverables? & Yes.
\end{tabular}

\begin{tabular}{l|l}
\hline If yes, describe. & Funding Objectives:
\end{tabular}

- Community-based efforts reach key populations, including people unaware of their HIV/Hepatitis C status, and link them to testing, prevention, treatment and care

\begin{tabular}{|c|c|}
\hline & $\begin{array}{l}\text { - Communities design and implement evidence-based front line projects to prevent } \\
\text { new and reoccurring infections } \\
\text { - } \\
\text { High impact interventions are brought to scale so that more people benefit from } \\
\text { - Community-based efforts reduce stigma toward populations disproportionately } \\
\text { affected by STBBI, including people living with HIC or hepatitis C } \\
\text { Expected outcomes: } \\
\text { - Increase the knowledge of effective evidence-based HIV, Hepatitis C or other } \\
\text { sexually transmitted infections } \\
\text { - Strengthen the capacity (skills and abilities) of key populations and target } \\
\text { audiences to prevent infections and to improve health outcomes related to STBBI } \\
\text { Strengthen the capacity (skills and abilities) of target audiences țprovide culturally safe } \\
\text { and stigma-free STBBI prevention, testing, treatment and care services }\end{array}$ \\
\hline Will the deliverables need to be supported through data? & Yes. \\
\hline \multicolumn{2}{|l|}{ If it's not obvious, can you infer? } \\
\hline If so, describe them. & $\begin{array}{l}\text { Almost entirely supported through data. } \\
\text { The programs funded must be evidence-based } \\
\text { It talks about increasing skills and knowledge to particular ends as it concerns HIV and/or } \\
\text { hepatitis C. } \\
\text { Skills based interventions - behavioral for example. } \\
\text { Knowledge - psychological for example. } \\
\text { Community based interventions - numbers of participants for example }\end{array}$ \\
\hline
\end{tabular}

